\title{
Biophysical methods used to generate tolerance to drought stress in seeds and plants: a review
}

\author{
Raul Romero-Galindo ${ }^{1}\left({ }^{0}\right.$, Claudia Hernández-Aguilar $^{1}{ }^{(0)}$, Arturo Dominguez-Pacheco ${ }^{1}{ }^{(\mathbb{D}}$, \\ Juan José Godina-Nava ${ }^{2}$, and Rumen Ivanov Tsonchev ${ }^{3}$ \\ ${ }^{1}$ National Polytechnic Institute, Sepi-Esime-Zacatenco, Programme in Systems Engineering-Biophysical Systems, \\ Professional Unit ‘Adolfo López Mateos', Alcaldía GAM, Col. Lindavista, CP 07738, Mexico City, Mexico \\ ${ }^{2}$ Department of Physics, Cinvestav-IPN, A.P. 14-740. 07360, Mexico City, Mexico \\ ${ }^{3}$ Academic Unit of Physics, Autonomy University of Zacatecas, A.P. 580, Zacatecas, Mexico
}

Received November 4, 2021; accepted December 14, 2021

\begin{abstract}
Drought stress has serious repercussions for agriculture, affecting crop growth with low yield effects concerning food production and food security. The main objective of this research is to conduct a scientific literature review of the physical methods used to generate tolerance to water stress in crops. (i) The most widely applied physical method to counteract the effects of drought stress is UV radiation, magnetic field application (18\%), $\mathrm{He}-\mathrm{Ne}$ and $\mathrm{CO}_{2}$ laser (18\%), gamma radiation (9\%) and plasma $(6 \%)$. (ii) Treatments with ultraviolet light and magnetic fields have been applied mainly in cereals, vegetables, legumes, medicinal plants, and trees. Also, $\mathrm{He}-\mathrm{Ne}, \mathrm{CO}_{2}$ laser, and plasma in seeds in cereals and medicinal plants in the pre-sowing stage to seed level. Finally, gamma radiation has been applied to plants and seeds (grass, flowers, sugar plant). (iii) The reported physical methods can increase or decrease the biochemical variables under water stress depending on the physical method and radiation parameters applied, as well as the crop, level of drought and the environment in which the plants develop. Thus, UV radiation, magnetic fields, gamma radiation, and $\mathrm{He}-\mathrm{Ne}$ and $\mathrm{CO}_{2}$ lasers are physical methods that produce seed and plant improvement effects.
\end{abstract}

Keywords: physical methods, drought stress, seed conditioning, tolerance to water stress

\section{INTRODUCTION}

Global food demand continues to grow, and there is a global challenge to feed 10 to 11 billion people by 2050 and 2100 (Azadi et al., 2018; Dillard, 2019). Moreover, global warming and the irrational use of natural resources

*Corresponding author e-mail: clauhaj@yahoo.com has an impact on food security (Saccon, 2018; Azadi et al., 2018). For example, one problem associated with global warming is drought, which affects agricultural production systems and, consequently, food-bearing plants for human consumption (Ali et al., 2020; Murray-Tortarolo et al., 2018; Mardero et al., 2018). Likewise, water stress promoted by drought in plants leads to reactive oxygen species (ROS) production, generating wilting in leaves, oxidative damage to proteins and cell membrane instability (Wang et al., 2018).

Also, climate change has generated alterations in hydrological patterns, which has led to a higher incidence of droughts and flooding which has affected the production of temporary crops (Ali et al., 2020; Arreguin et al., 2019; Murray-Tortarolo et al., 2018). Furthermore, the climatic phenomenon has generated changes in the behaviour of the agricultural system, which are manifesting themselves in the form of erosion, salinization, and a general decline in soil quality, leading to the abandonment of farmland.

At present, Mexico is experiencing changes in temperature and precipitation, resulting in a $25 \%$ decrease in crop yields such as corn production. Comparable data have reported a decrease (100 $\mathrm{mm}$ year $\left.^{-1}\right)$ and an increase (2000 $\mathrm{mm} /$ year), in precipitation in the north and south of the country respectively, during the period of 1901-2009 (Murray-Tortarolo et al., 2018). Additionally, significant

(C) 2021 Institute of Agrophysics, Polish Academy of Sciences 
losses of 45 and $83 \mathrm{mln} \mathrm{t}$ of corn and soybeans have also been reported in the United States due to severe drought during 2012 (Rodríguez-Calzada et al., 2019). Similarly, North Africa has suffered a $33 \%$ decrease in precipitation compared to the situation 40 years ago and it now represents one-tenth of the world's average water supply (FAO, 2014).

According to some authors, climate change will result in drought episodes causing a devastating impact on agricultural production systems, this may occur in Africa, Asia, Europe, China, and the Middle East, where many people would be threatened by a scarcity of this water resource as $10 \%$ of their agricultural land would be affected (Fitton et al., 2019). That is why it is vital to innovate using affordable and environmentally friendly techniques that would allow for an increase in the tolerance to drought stress without reducing agricultural yields, emphasize the responsible use of resources, especially natural resources, and support sustainable agriculture (Ali et al., 2020; Mardero et al., 2018; Rodríguez-Calzada et al., 2019). Among the environmentally friendly methods proposed to mitigate the aforementioned problems are those corresponding to seed conditioning as reported by (Thomas and Puthur, 2017).

Seed conditioning is a pre-sowing treatment that works as a stimulator of the plant's defence system and increases tolerance to drought stress (Hernández-Aguilar et al., 2006; 2010; Damalas et al., 2019; Thomas and Puthur, 2017; Waqas et al., 2019). Sustainable methods designed to improve this tolerance have been reported by several authors. These include physical methods such as ultraviolet (UV) radiation (three types are defined below), laser, magnetic (B) and electric fields (E), X-rays, ionizing radiation, microwaves and magnetically treated water (HernándezAguilar et al., 2009a; 2009b; 2016; 2021a; Thomas and Puthur, 2017; 2019; Rifna et al., 2019; Gudkov et al., 2019; Waqas et al., 2019).

Particular studies have been published in the scientific literature describing these methods, providing evidence for their possible usefulness in agricultural applications. The methods may be of the ionizing, non-ionizing and conventional type and so on.

Gudkov et al. (2019) analysed the effects produced by ionizing radiation at the physiological level, which among other effects, stimulates hydrogen peroxide production, emphasizing the point that it does not act as a causative agent of oxidative stress but rather as an intracellular messenger that interacts with different signalling mechanisms. Waqas et al. (2019) studied conditioning methods through the use of osmosis, nutrients, chemicals, water and biological agents to improve the germination percentage and stimulate the defence system of the plant. Radhakrishnan (2019) addressed the importance of using the B field to mitigate the effects of climate change and the inadequate use of agricultural resources for production, highlighting the conclusive evidence for using the B field to improve seed germination at specific concentrations and radiation parameters.

Thomas and Puthur (2017) describe the use of UV radiation as a seed conditioning method to stimulate germination and the production of bioactive compounds which are beneficial in overcoming both biotic and abiotic stress conditions. Also, laser applications have been reported as a biostimulator element of seeds and plants, finding different applications for the improvement of the physiological, microbiological parameters and also the nutritional quality (Hernández-Aguilar et al., 2010; 2016).

Rifna et al. (2019) discuss the methods of high pressure, pulsed E field, ultrasound, ozone, UV radiation, B field, microwave radiation, non-thermal plasma, electrolysed water and plasma-activated water, focusing on the positive and negative impacts of these technologies on the germination process.

The Helium-Neon (He-Ne) laser has been used to irradiate the seeds of Celosia and scarlet sage in order to counteract the effects produced by water stress, thereby obtaining favourable results at the plant level and an increase in the production of antioxidants (El-Salami et al., 2019; Ali et al., 2020). On the other hand, the $\mathrm{CO}_{2}$ laser used on wheat seeds reduces oxidizing compounds that affect the plant system (Qiu et al., 2008). In the same way, UV-B light used on bean seeds, lettuce plants, and wheat seedlings promotes the production of antioxidant compounds. These antioxidants help to decrease the damage caused by water stress. Furthermore, due to the tolerance of a lack of irrigation, plant growth is affected (Balakumar et al., 1993; Basahi, 2014; Alexieva et al., 2001).

The B field is another method that has been studied to mitigate the damage caused by drought; it has been used in tomato and soybean seeds, to obtain beneficial results in plant growth and in the production of bioactive compounds. Additionally, it decreases the production of oxidative stress markers (Mohammadi and Roshandel, 2020; Selim and El-Nady, 2011; Baghel et al., 2018). In the same way, gamma-ray radiation diminishes the production of oxidative compounds and increases the amount of antioxidants in sugar cane plants and grass (Mirajkar et al., 2019; Lu et al., 2008). Finally, the use of plasma in Nasturtium seed and wheat, apart from increasing the water absorption capacity, also increases both the percentage of germination and antioxidant concentration (Guo et al., 2017).

There are specialized literature reviews concerning physical methods and their effects on seeds and plants, however, despite this, to date there are no articles reviewing these methods in applications designed to precondition seeds and plants in a drought situation. This thorough literature review highlights the physiological and biochemical effects of applying physical methods (UV light, B field, $\mathrm{He}-\mathrm{Ne}$, and $\mathrm{CO}_{2}$ laser, gamma irradiation, and plasma application) during the different phenomenological stages 


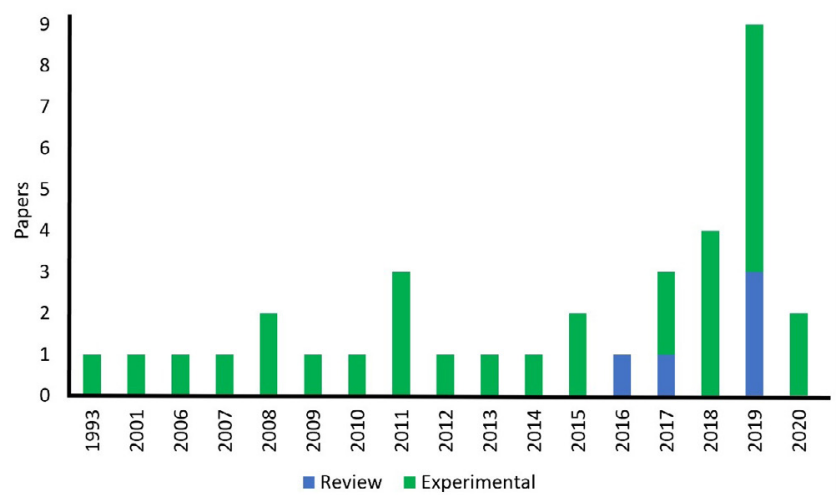

Fig. 1. Articles published per year related to biophysics methods used to enhance crop water stress tolerance.

of crops under drought stress conditions. All of these methodologies are proposed to address the problem of drought stress prevalent in the agricultural field, since it is well known that climate change alterations have caused drought problems that compromise crops which are grown in the interest of humanity.

\section{MATERIALS AND METHODS}

The literature review was conducted from February May 2021. The MDPI, Wiley, ScienceDirect, Nature and Springer link databases were reviewed as was the academic Google search engine. The logical descriptors used in the search process were (Priming, radiation, drought, ,water stress", „Physical methods”, alone and associated, excluding ,elicitor”). Similarly, Boolean operators were used such as (,water stress" OR “drought” OR ,hydric stress”) AND (,physical methods" OR "laser” OR "radiation” OR "magnetic") and (,water stress" OR “drought”) and ("radiation" OR ,physical methods" OR “laser”).

The selection criteria were related to drought stress in crops, seed conditioning, food safety and biophysical methods applied to agriculture, without any publication date restriction. Furthermore, the snowball method was used to select other articles related to seed and plant conditioning. For the classification of the literature found, a Python program was created, which extracts descriptors such as the year of publication, author, method, the subject of the study and the type of publication. Mendeley Desktop software, version 1.19.4, was used to generate citations and reference lists of the articles reviewed.

\section{RESULTS AND DISCUSSION}

In this documentary research, 76 scientific articles were found, of which 18 were review-type articles, and 58 were experimental articles. After filtering the information, only 13 review articles and 49 articles concerning experimental activity were selected. Figure 1 shows an increasing trend in the number of studies concerning the subject, with a greater number of articles in 2019. Likewise, the method of most significant interest used to mitigate the effects of

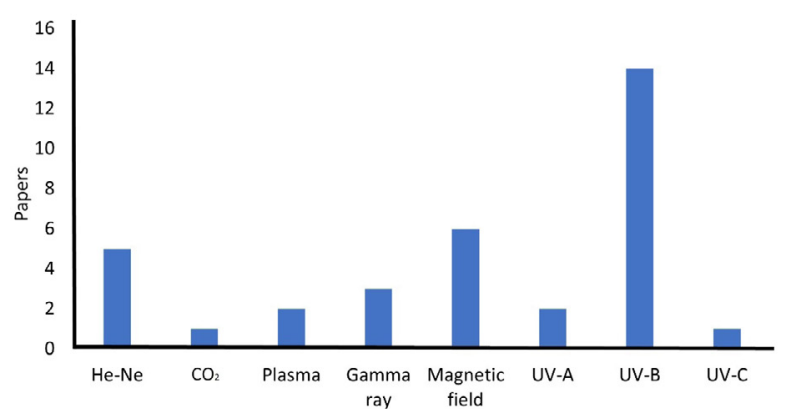

Fig. 2. Article classification according to the physical treatment used. He-Ne laser means Helium-Neon laser, $\mathrm{CO}_{2}$ laser means carbon dioxide laser, DBD - means dielectric barrier discharge.

water stress is UV radiation (Fig. 2), this represents $48 \%$ of the articles reviewed, followed by B field (18\%), He-Ne laser $(15 \%)$, gamma irradiation $(9 \%)$, plasma $(6 \%)$, and $\mathrm{CO}_{2}(3 \%)$.

The most relevant findings concerning the biophysical methods applied to seeds and plants to generate tolerance to drought stress are discussed below. Firstly, the mechanisms of plant response to water stress are included, starting with the current understanding of water stress and the response of plants at different stages of their development. Subsequently, the physical methods that have been applied to increase tolerance to drought stress are presented.

Stress is a restriction imposed on metabolic patterns originating from factors that disrupt the plant's equilibrium thereby generating a condition of physiological alteration, injury, or disease (Shao et al., 2009a; 2009b). Other authors have referred to the presence of an external factor that has an adverse influence on the plant, this may be divided into biotic and abiotic stress. Biotic stress is the damage generated by a biological agent such as insects, fungi, bacteria and nematodes among others and abiotic stress is the physical damage imposed by the environment such as light, temperature, humidity, water, or chemical agents (Nejat and Mantri, 2017). 
Drought stress is an abiotic stress factor caused by a water deficit that can generate drought (Ihuoma and Madramootoo, 2017). In response to this stress, plants are affected by biochemical and morphological changes, generated by dehydration in the cell structure. In this way, increased ROS production generates decreased photosynthetic activity, changes in stomatal conductance, it affects pigment content and decreases plant growth. All of these conditions are reflected in a low agricultural production yield (Qiu et al., 2018; Thomas and Phutur, 2019; Sangtarash et al., 2009). Cellular dehydration or desiccation results in far more extensive water losses that can generate irreversible damage thereby compromising plant development (Plancot et al., 2019).

As an initial biochemical response to water stress, plants produce ROS thereby generating a wilting of the leaves, oxidative damage to proteins and cell membrane instability (Wang et al., 2018). Also, many phytochemical compounds are induced by ROS, ethylene, and abiotic factors (Surjadinata et al., 2017). In this multitude, flavonoids stand out as a group of phenolic compounds, and one of their main characteristics is that they function as antioxidants which allows for favourable plant development despite the challenges of different forms of stress (Rodríguez-Calzada et al., 2019). Other compounds such as carotenoids, help to neutralize ROS through their antioxidant function, they also protect the photosynthetic apparatus and its associated pigments (Thomas and Puthur, 2019).

Water deficit or salinity stress in plants develop due to the increased production of ethylene and abscisic acid (ABA), this generates networks sensitive to abiotic stress (Rifna et al., 2019; Thomas and Puthur, 2017; Gudkov et al., 2019). Nonetheless, many antioxidant enzymes have been studied for their efficient regulation of ROS and the mitigation of the adverse effects caused by droughts. Such is the case with carotenoids, flavonoids and superoxide dis- mutase (SOD) which aid in the detoxification of superoxide radicals, peroxidases (PODs) that produce the oxidation of phenols, malondialdehyde (MDA) as a product of lipid peroxidation is considered to be an index of injury by oxidative damage (Lu et al., 2008). Hydrogen peroxide, tannin compounds, catalases (CATs), ascorbate peroxidases (APXs), glutathione (GSH) and ascorbate which plays an essential role in catalysing and dissociating hydrogen peroxide to protect the cells from oxidative damage (Fig. 3), and at the same time aiding the reduction of ROS (Feng et al., 2007; Qiu et al., 2018; El-Sallami et al., 2019; Wang et al., 2018; Rajabbeigi et al., 2013; Thomas and Puthur, 2017). As mentioned above, these antioxidant enzymes help to combat the adverse effects of ROS, however, the oxidative damage alone produces an inadequate response in the plant defence system (Qiu et al., 2008).

Light has been used to control morphogenesis, photosynthesis and growth and to promote resistance to photon flux damage in plants as they receive light at different wavelengths, intensities and exposure times (Anders and Essen, 2015). This light is identified by different colour segments of the electromagnetic spectrum such as UV (A: $315-380$ $\mathrm{nm}$, B: $280-315 \mathrm{~nm}$, and C: $100-280 \mathrm{~nm})$, blue (400-500 $\mathrm{nm})$, green $(500-600 \mathrm{~nm})$, red $(600-700 \mathrm{~nm})$ and near red (700-800 nm) light.

Plants use different photoreceptors for each band of the electromagnetic spectrum, such as phytochromes for red and near red light and cryptochrome and phytochrome for the UV-B and UV-A ranges (Kang et al., 2020; Paik and Huq, 2019; Rodriguez-Calzada et al., 2019). Solar UV-A and UV-B radiation are natural stressors that generate bioactive compounds in plants such as carotenoids that protect chlorophyll (Chl) molecules from the excess energy produced by photosynthesis (Mariz - Ponte et al., 2018). With regard to this and other types of stresses, the usefulness of different seed conditioning methods has been found to

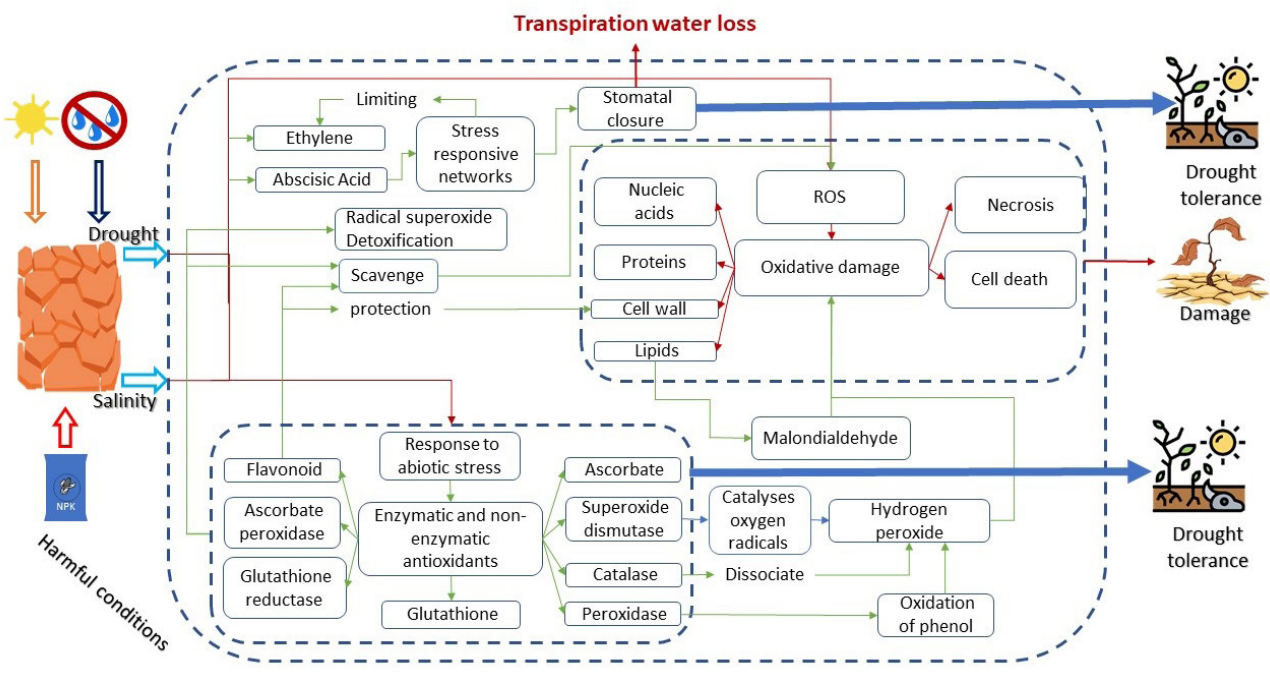

Fig. 3. Enzymatic and non-enzymatic antioxidants involved in counteracting the effects produced by ROS. 
increase the tolerance of the plant to the types of stresses that may occur in plants. Methods to generate seed conditioning for drought stress will be addressed.

Seed conditioning is a pre-sowing and early germination stage treatment that stimulates physiological processes including the defence system of the plant. It is currently being used to improve survival and overcome the adverse effects caused by abiotic stress (Damalas et al., 2019; Thomas and Puthur, 2017; Waqas et al., 2019). This effect is induced because plants undergoing conditioning remain in a positive response state, and as the dose level leaves that threshold, damage or inhibition of the biological response (i.e., hormesis) occurs. Given its importance, it has been studied in a significant number of organisms (Agathokleous et al., 2019).

Seed conditioning has been used throughout history to improve the characteristics and germination of plants. When humankind finally managed to settle in a single place, they knew of and experimented with seeds to produce their food. Later they realized that not all seeds germinated, for those that did germination depended on the season of the year, for some it depended on temperature, for others on the humidity, the kind of substrate, among other factors (Evenari, 1984). In such an era, they looked for ways to promote germination. Such was the case with the naturalist Plinius Secundus (B.C. 23-79), who emphasized pre-sowing treatment with honey and water to increase germination in cucumber seeds. Also, the philosopher Theophrastus (371 - 287 A.D.) experimented with milk and water to treat cucumber seeds and increase germination (Paparella et al., 2015)

On the other hand, Democritus said that before sowing the seeds, it was necessary to soak them with the "juice of the plant that grows on the shingles" (Thanos and Georghiou, 1988). Similarly, Oliver de Serres (1539-1619) described a treatment used by farmers on wheat, rye, and barley seeds where they were dipped in dung broth and subsequently placed in the shade, dried, and sown. Over time, the interest of several naturalists in seed treatment increased, as was the case of Charles Darwin (1809-1882), who osmotically conditioned the seeds of garden cress (Lepidium sativum L.) and lettuce (Lactuca sativa L.) to increase the germination percentage (Paparella et al., 2015).

The effects of the physical methods were studied starting at the end of the first third of the 20th century. Such was the case with Savostin's (1964) research, who reported an increase in the percentage of elongation in wheat seedlings when he applied a B field. Similarly, Murphy (1942) applied a B field for short periods on seeds and observed an acceleration in germination time and seedling growth. Other authors have reported the effects of the B field on plant growth and development (Flórez et al., 2007; Hussein et al., 2012).
The effects of light on seeds have been studied since the last century (Hernández-Aguilar et al., 2010). Flint and Mcalister (1935) observed that the germination of lettuce (Lactuca sativa L.) seeds was promoted by red light and inhibited by far-red light. From this process, Flint proposed the existence of two photoreceptors (phytochrome and cryptochrome). Sometime later, Borthwick et al. (1952) observed that the inhibition of germination due to far-red light could be reversed by applying red light. From this point on, a range of possibilities was opened for the application of physical methods at the seed and plant level to improve their quality.

Physical methods are a type of seed conditioning considered to be adequate, safe, easy, efficient and sustainable (Hernández-Aguilar et al., 2009b) which could be potentially useful for improving drought stress tolerance. Chemical methods that cause damage to the environment and consumers remain an undesirable option for plant breeding (Thomas and Puthur, 2019; Velichko et al., 2019; Mohammadi and Roshandel, 2020).

Currently, various physical methods have been reported which generate water stress tolerance in seeds and plants, such as UV radiation, B field, $\mathrm{He}-\mathrm{Ne}$, and $\mathrm{CO}_{2}$ lasers, gamma rays, $\mathrm{X}$-rays, ionizing radiation, microwaves, a dielectric barrier discharge and magnetically treated water (Hernández-Aguilar et al., 2016; Kornarzyński et al., 2018; Selim and El-Nady, 2011; Thomas and Puthur, 2017). These methods generate a positive biochemical response like that of abiotic stress. The difference is that there is little or no alteration at the level of growth parameters which is positive in yield (Thomas and Puthur, 2017). In tomato (Lycopersicum esculentum L. cv. Strain) seeds irrigated with magnetically treated water and subjected to water stress, their physiological parameters include increased proline and photosynthetic pigments and also growth parameters like plant height and stem thickness improved (Selim and El-Nady, 2011).

Numerous studies have shown the effects of physical methods used to increase the water stress tolerance of plants. Experimental laboratory and field trials have been conducted and reported in the scientific literature, showing the effects on different seeds, seedlings and plants. This review addresses the physical methods that have been studied using different irradiation parameters (dose, exposure time, intensity, among others, depending on the method applied) to increase crop tolerance to drought stress: UV light, B field, laser, gamma, and plasma application (Fig. 4).

UV light is divided into UV-A $(320-390 \mathrm{~nm})$, UV-B (280-320 nm), and UV-C (values below $280 \mathrm{~nm}$ ). This radiation works as a natural elicitor with a physiological and biochemical impact on plants (Danon and Gallois, 1998; Rajabbeigi et al., 2013). Also, UV-B radiation and water stress promote ethylene production, limiting plant growth and reducing leaf area and dry weight, among other effects. These conditions have a direct impact on agricultural yields, 


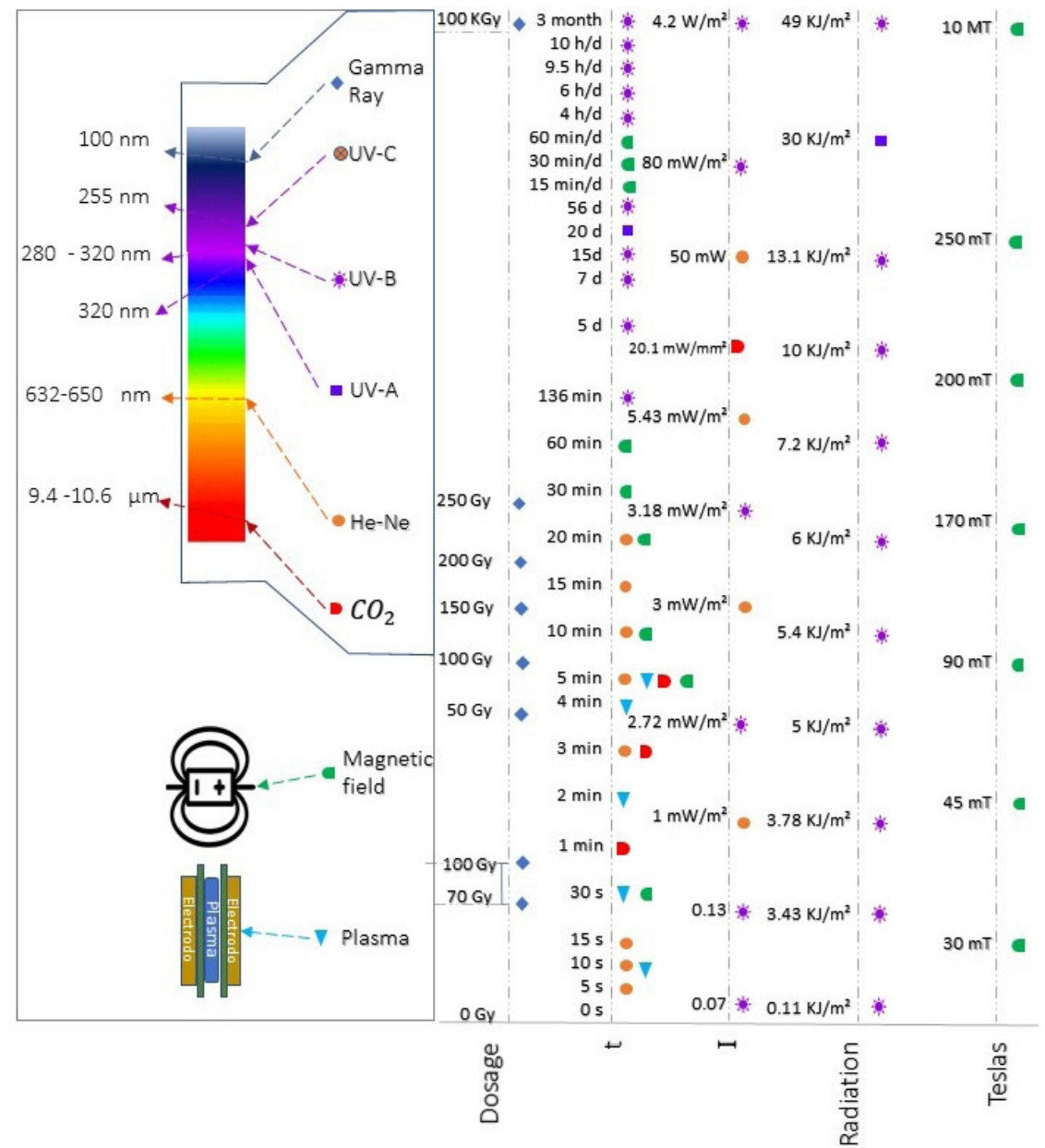

Fig. 4. Biophysical methods to generate drought stress tolerance: irradiation parameters.

and finally, on consumers since they affect the nutritional properties of the food (Sangtarash et al., 2009). The effects associated with UV-B light on Hordeum vulgare L. plants have been counteracted by treatment with UV-A light at an intensity of $3 \mathrm{~W} \mathrm{~m}^{-2}$ for $16 \mathrm{~h}$ per day throughout a 6 day period, thereby resulting in an increase in the assimilation of $\mathrm{CO}_{2}$, Chl, and carotenoid content (Štroch et al., 2015).

UV light in region B (280-320 $\mathrm{nm})$ has been applied during different exposure times of 2.2-2 $160 \mathrm{~h}$ using fluorescent or mercury lamps, and LEDs. Scientific evidence indicates that the treatment of seeds utilizing UV light in their different phenological stages, under water stress, allows for the reduction of the adverse effects produced. Such an effect develops as the application of the radiation influences the functional processes of plants (Basahi et al., 2014). Thus, there are positive and negative effects due to UV light treatment, depending on the electromagnetic region applied.

Mariz-Ponte et al. (2018), applied UV-A light (0.8 J $\mathrm{m}^{-2}$ ) and UV-B $\left(2.94 \mathrm{~W} \mathrm{~m}^{-2}\right)$ using fluorescent lamps for four hours and five minutes on plants, respectively. In this way, stress was produced in tomato plants (Solanum $c v$.
MicroTom), which led to the stimulation of oxidative stress mechanisms, leading to an increase in SOD activity and $\mathrm{H}_{2} \mathrm{O}_{2}$. Rodríguez-Calzada et al. (2019) irradiated "chili" plants (Capsicum annum, cv. 'coronel') with UV-B fluorescent lamps at an intensity of $80 \mathrm{~mW} \mathrm{~m}^{-2}$, for four hours per day in order to evaluate the response to drought stress.

It was found that the application of UV-B light led to a reduction in stem length, dry stem weight and in the number of flower sprouts. Studies have shown that UV-B light treatment does not lead to gene expression associated with an oxidative response such as SOD and POD but rather, directly affects plant development. Other authors have confirmed that water stress and UV-B radiation in plants limits leaf growth as a part of their protection mechanism against these stress conditions (Basahi et al., 2014).

In an experiment conducted by Alexieva et al. (2011) pea seedlings (Pisum sativum L.) and wheat (Triticum) were subjected to drought after day 7 and day 10 of growth. Subsequently, they were treated with a mercury lamp UV-B (280-320 nm) for two hours a day. Both UV-B treated seedlings showed effects in terms of plant height as well as dry and fresh weight. 


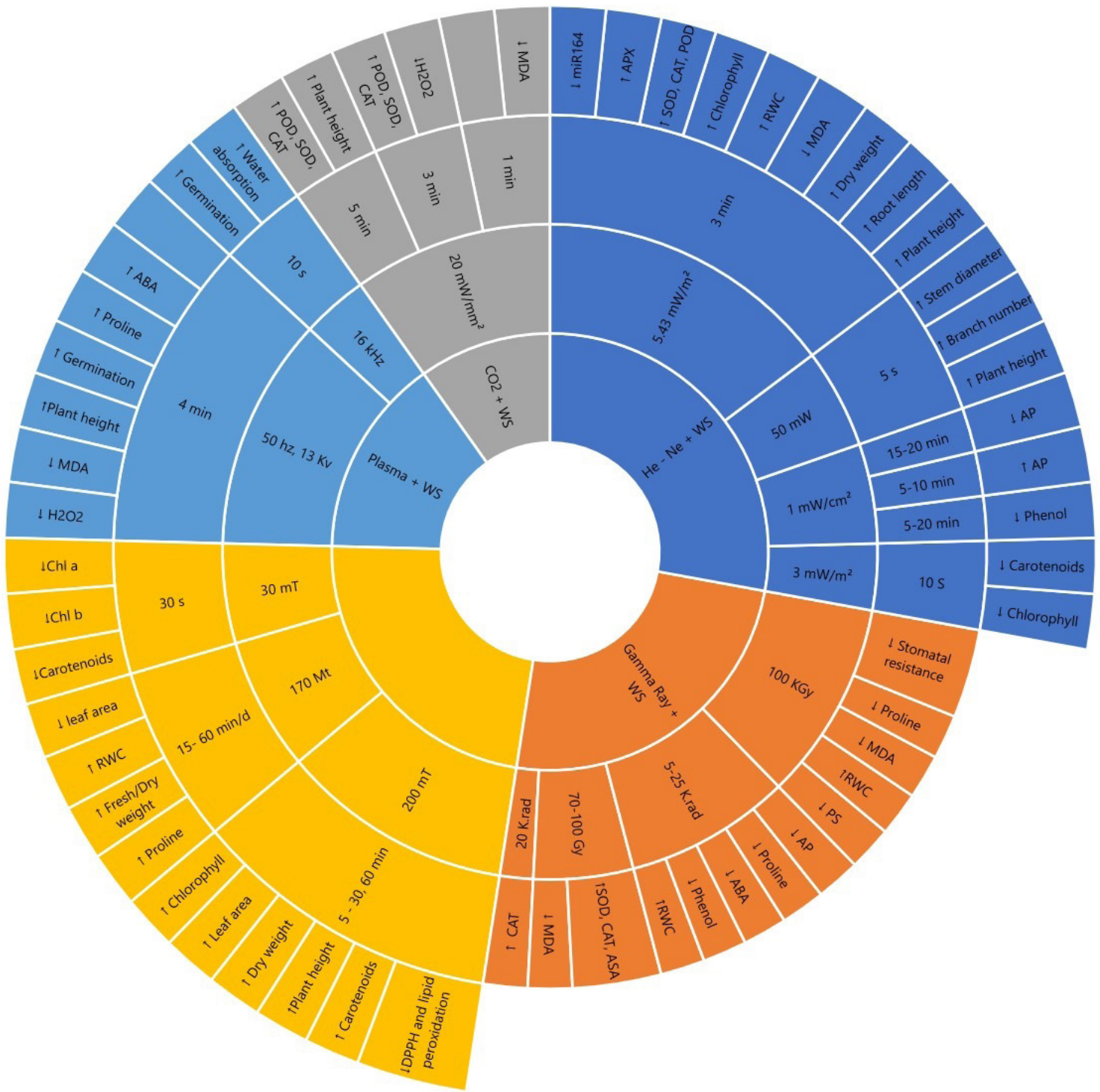

Fig. 5. Physical methods, their parameters and their positive or negative effects on variable response.

Otherwise, CAT, POD and SOD activities increased in pea and decreased in wheat for three enzyme activities. Seedlings subjected to water stress reduced their relative water content (RWC) in leaves. Pea seedlings increased in POD activity and decreased in SOD and CAT. In wheat, CAT and SOD activity increased. Finally, when both stressors were combined, the negative effects were balanced in both crops, and the enzyme activities did not represent significant changes.

Likewise, Basahi et al. (2014) conducted experiments with lettuce seedlings (Lactuca sativa L. Romaine), applying two irrigation regimes (saturated and unsaturated soil) and light UV-B (300 nm) with a fluorescent lamp at doses of $5 \mathrm{~kJ} \mathrm{~m}^{-2}$ for $10 \mathrm{~h}$ per day. Subsequently, the plants were subjected to drought stress, a decrease in RWC and photo- synthetic content of 80 and $23 \%$ were observed. With the application of UV-B, these variables decreased by 90 and $13 \%$.

By contrast, the anthocyanin content had increased by $114 \%$ compared to the control. Similarly, the carotenoid, phenol, anthocyanin and flavonoid variables increased due to drought stress. Therefore, it is crucial to note that when both conditions (drought and UV-B) are applied, they induce a lower increase concerning those obtained in drought conditions or UV-B than the control. Also, there was an increase in anthocyanins (33\%), carotenoids $(25 \%)$, flavonoids (120\%) and phenols (20\%).

Other authors, such as Rajabbeigi et al. (2013), studied the effects of UV-B light on drought using lettuce (Lactuca sativa L.) plants. They applied three irrigation regimes (100\% irrigation (control), 45 and $25 \%$ soil water) during 
the entire crop cycle and UV-B light (305-310 nm) at a dose of $0.11 \mathrm{~kJ} \mathrm{~m}^{-2}$ using a fluorescent lamp for 5 days, two weeks before harvest. The reported findings were that when water stress and UV-B radiation were combined, there was an increase in Phenylalanine Ammonia-Lyase (PAL) activity (43\%), and an increase in dry weight $(8 \%)$, proline $(35 \%)$, lutein $(8 \%)$ and anthocyanins $(33 \%)$ as compared to the control plants. Even so, a decrease in quercetin (18\%) and biomass $(40 \%)$ is observed.

Another study conducted by Shen et al. (2010) showed that the application of $5.4 \mathrm{~kJ} \mathrm{~m}^{-2}$ of UV-B radiation (290$320 \mathrm{~nm}$ ) together with moderate water stress in soybean (Glycine max L.) plants increased the production of CAT $(100 \%)$, POD $(300 \%)$, SOD $(33 \%)$, hydrogen peroxidase $(68 \%)$ and lipid peroxidation (33\%) as compared to the control plants. However, a decrease in Chl content (30\%) was also found.

UV-C light is mainly used in sterilization systems and safety management (Danon and Gallois, 1998; HernándezAguilar et al., 2021b). In addition, it generates ROSmediated mechanisms that promote the production of secondary metabolites. This mechanism is due to alterations in the metabolic enzymes triggered, these are triggered by photochemical reactions during the breaking of chemical bonds (Mishra et al., 2020).

An example of the abovementioned phenomenon is the case of experiments in which an accumulated dose of UV-C radiation $\left(10.2 \mathrm{~kJ} \mathrm{~m}^{-2}\right)$ is applied to strawberry plants and a hormetic region is established where the expression of phenols, terpenes and genes associated with plant-pathogen interaction is induced, which generated a defence response to Mycosphaerella fragariae (Xu et al., 2019). This region was also irradiated with a single dose of UV-C $(0.85 \mathrm{~kJ}$ $\mathrm{m}^{-2}$ ) in tomato plants before harvest, with a $51 \%$ decrease in infection caused by Botrytis cinerea $\mathrm{L}$. This decrease is associated with increased Phenolic lipid (PL) and phenols produced in response to hormesis (Vàsquez et al., 2020).

Other experiments have also demonstrated this result, such was the case with Martínez-Sánchez et al. (2019), who observed an increase in the total phenol content when applying five radiation regimes of UV-C $(0.3 \mathrm{~kJ}$ $\mathrm{m}^{-2}$ ) in spinach leaves (Spinacia oleracea). Conversely, Surjadinata et al. (2017) conducted an experiment where they applied UV-C light to carrot (Daucus carota) slices using a mercury-vapour lamp at an intensity of $11.8 \mathrm{~W} \mathrm{~m}^{-2}$ for $15 \mathrm{~min}$. The results showed an increase in total phenol content (111\%) and antioxidant activity (>100\%) compared to the control samples (Surjadinata et al., 2017).

On the contrary, Martínez-Hernández (2020) found that the application of UV-C light at doses of $4 \mathrm{~kJ} \mathrm{~m}^{-2}$ together with $60 \%$ water availability with the requirements of the sweet cherry crop increased the production of phenolic compounds and antioxidant capacity by 21 and $36 \%$ during the shelf life of the harvested fruits when compared to the control samples.
The UV-B region seems to be the range of UV light with the most favourable effects on the plant. Positive effects on the production of CAT, POD anthocyanins, proline and relative water content in all crops may be attributed to growth restricted by stress factors, which activate radical scavenging mechanisms that prevent irreversible damage (Rajabbeigi et al., 2013). Nevertheless, Pisum sativum L. and Lactuca sativa L. crop phenols decrease (Alexieva et al., 2001; Rajabbeigi et al., 2013). However, they increase in Oryza sativa L., Brassica oleracea L., Glycine max L., Triticum aestivum L., and Vigna unguiculata L. (Thomas and Puthur, 2019; Yoon et al., 2020; Shen et al., 2010; Alexieva et al., 2001).

UV-B radiation modifies both phenols and other pigments. The modification is attributed to plant protection against drought. However, some authors argue that this improvement may be attributed to leaf thickening and the accumulation of pigments such as anthocyanins, carotenoids and phenols induced by UV-B radiation (Alexieva et al., 2001; Feng et al., 2007).

Furthermore, Basahi et al. (2014) state that UV radiation and drought affect the apparent quantum efficiency, damaging electron transport in the photosystem II. This response acts as a defence mechanism to prevent the radiation's penetration into plant tissues and thus protect the photosystem. Notwithstanding, irreversible damage occurs when these fail, affecting Chl content and other compounds (Alexieva et al., 2001; Feng et al., 2007). For this reason, some authors suggest using Chl content as an indicator of induced stress in plant leaves (Basahi et al., 2014).

In the case of SOD, it increases in all reported crops (Table 1) except for Rosularia elymaitica (Habibi and Hajiboland, 2011) and certain crops MDA (Triticum aestivum L., Oryza sativa L.) and $\mathrm{H}_{2} \mathrm{O}_{2}$ (Triticum aestivum L.) and decreases in Lactuca sativa L. and Pisum sativum L., respectively (Alexieva et al., 2001; Feng et al., 2007; Basahi, 2014; Thomas and Puthur, 2019). Similarly, for phosphatidic acid (PA), the same behaviour as for $\mathrm{H}_{2} \mathrm{O}_{2}$ was observed for the species mentioned above. In other studies, APX, and Chl increase in Rosularia elymaitica (Crassulaceae) and Glycine $\max$ L. (Habibi and Hajiboland, 2011; Shen et al., 2010), respectively. Similarly, other metabolites are modified, as is the case with quercetin, the content of which decreases in Lactuca sativa L. (Rajabbeigi et al., 2013) and the content of flavonoids increases (Triticum aestivum L., Brassica napus L., Capsicum annuum L. and Brassica oleracea L.) and decreases (Lactuca sativa L. and Betula pendula Roth) according to several authors (Feng et al., 2007; Sangtarash et al., 2009; Basahi, 2014; Robson et al., 2015; Rodríguez-Calzada et al., 2019; Yoon et al., 2020).

Specific authors have reported that increased $\mathrm{H}_{2} \mathrm{O}_{2}$ is a consequence of abiotic stress and is utilized by APX, SOD and CAT enzymes due to a response of both stressors, i.e., $\mathrm{UV}+\mathrm{B}$ and water stress (Basahi et al., 2014). Furthermore, water stress-induced proline synthesis has been shown to 
Table 1. Biophysical methods used at seed and seedling level to stimulate water stress tolerance in different crop species

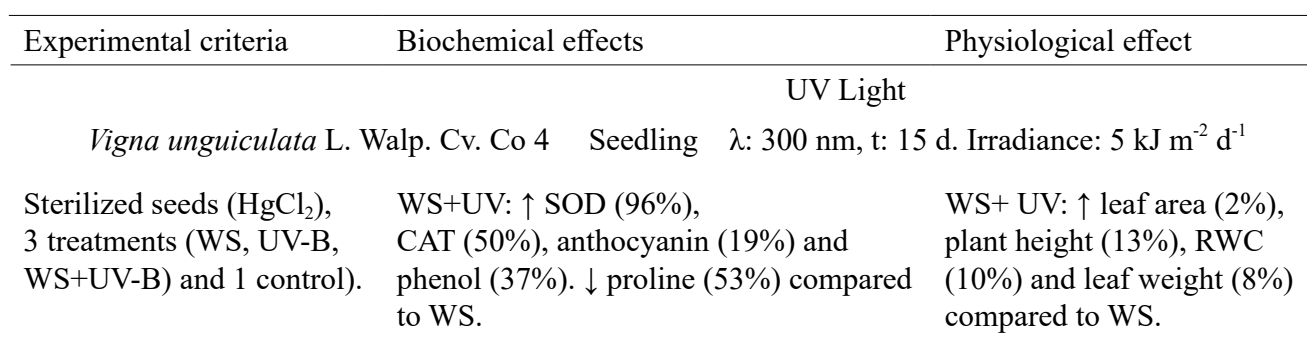

Pisum sativum L. Seedling $\lambda: 280-320 \mathrm{~nm}, \mathrm{t}: 7 \mathrm{~d}$, Irradiance: $49 \mathrm{~kJ} \mathrm{~m}^{-2} \mathrm{~d}^{-1}$

3 T: WS, UV-B, WS+UVB， WS+UV: $\uparrow$ SOD, CAT, and anthocyanin $\quad \mathrm{WS}+\mathrm{UV}: \uparrow$ RWC (16\%), and control. PEG6000 was $\quad\left(108,140\right.$ and 107\%). $\downarrow \mathrm{H}_{2} \mathrm{O}_{2}$, phenol and $\quad$ DW and leaf area (7\%). $\downarrow$ used to induce drought $\quad \mathrm{PA}$ stress. (7, 9 and $11 \%$ ) compared to EH. plant height and FW $(6$ and $7 \%$ ) compared with WS.

Triticum aestivum $\mathrm{L}$. Seedling $\lambda: 280-320 \mathrm{~nm}, \mathrm{t}: 7 \mathrm{~d}$, Irradiance: $49 \mathrm{~kJ} \mathrm{~m}^{-2} \mathrm{~d}^{-1}$

3 T: WS, UV-B, WS+UV-B, and control. PEG6000 was used to induce drought stress.
WS+UV: $\uparrow$ CAT (163\%), SOD (200\%), anthocyanin (142\%), phenol (79\%), $\mathrm{H}_{2} \mathrm{O}_{2}$ $(12 \%)$, PA (44\%) compared to WS.
WS+UV: $\uparrow$ Plant height, $\mathrm{DW}, \mathrm{FW}$, leaf area and RWC $(2,10,4,8,16 \%)$ compared with WS.

Myrsinifolia Seedling $\quad \lambda: 280-320 \mathrm{~nm}, \mathrm{t}: 136 \mathrm{~min}$, Irradiance: $3.6,7.2 \mathrm{~kJ} \mathrm{~m}^{-2} \mathrm{~d}^{-1}$

\begin{abstract}
4 T: 2 levels UV-B (Solar -
filtered and artificial), 2 water regimes (100 and $50 \%$ ).
\end{abstract}

$\downarrow$ Biomass, stem length, root and leaf area in all treatments compared with WS.

Reference

Balakumar et al. (1993).

Alexieva et al. (2001) in that both stresses provoke an oxidative burst. The purpose of this investigation was to compare the effects and interaction of drought and UV-B in wheat and pea. The absence of changes in relative leaf water content (RWC).

Turtola et al. (2006).

Triticum aestivum $\mathrm{L}$. Seedling $\lambda: 300 \mathrm{~nm}$, radiation: Irradiance: $13.1 \mathrm{~kJ} \mathrm{~m}^{-2} \mathrm{~d}^{-1}$

ED completely randomized WS+UV: $\uparrow$ Flavonoids, MDA with 3 cultivars, 3 T: 2 in the three cultivars compared irrigation levels and 1 of to EH. radiation with 8 repetitions.

\section{Brassica napus L.}

Treated plants 7 DAT: 2,3 and 2 irrigation levels, irradiation UV-B and AA.
WS+UV: $\downarrow$ Plant height, leaf area and yield of the three cultivars in comparison with WS.

\section{Seedling $\quad \lambda: 300 \mathrm{~nm}$, Irradiance: $0,5,10 \mathrm{~kJ} \mathrm{~m}^{-2} \mathrm{~d}^{-1}, \mathrm{~T}: 9.5 \mathrm{~h} \mathrm{~d}^{-1}$}

UV-B: $\uparrow$ Carotenoids, flavonoids, chlorophyll, and ethylene compared to plants not stressed with UV-B.
UV-B: $\downarrow$ Leaf size and area and stem length in comparison to unstressed plants with UV-B.

Glycine $\max \mathrm{L}$. Seedling $\lambda: 300 \mathrm{~nm}$, Irradiance: $5.4 \mathrm{~kJ} \mathrm{~m}^{-2} \mathrm{~d}^{-1}$

$\mathrm{T}$ completely randomized, induction to WS with $20 \%$ of PEG, 8 T, 4 repetitions.
WS+UV: $\uparrow$ Anthocyanin, POD, phenol, SOD, H-POD $(50,168,13,82,11 \%) . \downarrow$ CAT, Chl (34, 48\%) compared to WS. $\uparrow \mathrm{DW}$ of root $(10 \%)$ and RWC (8\%) compared to WS.

Rosularia elymaitica (Crassulaceae) Plant $\lambda: 300,320 \mathrm{~nm}, \mathrm{t}: 6 \mathrm{~h} \mathrm{~d}^{-1}$ during $20 \mathrm{~d}$, radiation:30 $\mathrm{kJ} \mathrm{m}^{-2}$

$\mathrm{CP}$ watered twice a week and plants with WS watered every $20 \mathrm{~d}$ with distilled water.
UVA+B: $\downarrow$ Activity SOD (13\%), $\uparrow$ APX and CAT compared to WS.
UVA+B: $\downarrow$ Dry weight, fresh weight. $\uparrow \mathrm{RWC}, \Psi \mathrm{H}$ and leaf area compared to WS.
Feng et al. (2007).

Sangtarash et al. (2009).
Shen et al. (2010).
Habibi and Hajiboland (2011)

\section{Lactuca sativa L. Plant $\lambda: 305-310 \mathrm{~nm}, 0.11 \mathrm{~kJ} \mathrm{~m}^{-2}, \mathrm{t}: 5 \mathrm{~d}$}

Randomized block design, WS+UV: $\downarrow$ Quercetin, anthocyanins, $\mathrm{T}$ (WS, no WS, V-B and no phenols, lutein UV-B 2 weeks before $(21,14,13,26 \%) \cdot \uparrow$ proline, PAL $(15,49 \%)$ compared to WS. harvest).
WS+UV: $\downarrow$ Biomass $(22 \%)$ and dry weight $(5 \%)$ compared to WS.

T: Treatment, $\lambda$ : Wavelength, WS: Water Stress, DAT: $d$ after transplantation, MDA: Malondialdehyde, PA: Peroxidase activity, SOD: Superoxide dismutase, DW: dry weight, FW: fresh, AA: Abscisic acid, weight, POD: Peroxidase, APX: Ascorbate peroxidase, CAT: Catalase, CP: Control plants, RWC: Relative water content, ED: Experimental design, $\downarrow$ : Decrease, $\uparrow:$ Increase, $\Psi H$ : Water potential. 
Table 1. Continuation

\begin{tabular}{|c|c|c|c|}
\hline Experimental criteria & Biochemical effects & Physiological effect & Reference \\
\hline \multicolumn{4}{|c|}{ Lactuca sativa L. cv. Romaine Plant $\lambda: 290-320 \mathrm{~nm}, \mathrm{t}: 10 \mathrm{~h} \mathrm{~d}^{-1}$, Irradiance: $5 \mathrm{~kJ} \mathrm{~m}^{-2} \mathrm{~d}^{-1}$} \\
\hline $\begin{array}{l}\text { Factorial arrangement with } \\
\text { completely randomized blocks, } 4 \\
\text { replications, two factors: UV-B } \\
\text { and WS with } 2 \text { regimes. }\end{array}$ & $\begin{array}{l}\text { WS+UV: } \uparrow \text { Anthocyanins }(39 \%) \text {, } \\
\text { SOD }(56 \%) \text {, CAT }(70 \%) . \downarrow \\
\text { flavonoids }(33 \%) \text {, carotenoids } \\
(24 \%) \text {, phenols }(8 \%) \text {, proline } \\
(28 \%), \text { MDA }(9 \%) \text { compared to } \\
\text { WS. }\end{array}$ & $\begin{array}{l}\text { WS+UV: } \uparrow \text { CRA }(16 \%), \text { number of } \\
\text { leaves }(13 \%) \text {, fresh weight }(11 \%) \\
\text { and dry }(27 \%) \text { and leaf length no } \\
\text { difference compared to WS }\end{array}$ & Basahi (2014). \\
\hline \multicolumn{4}{|c|}{ Betula pendula Roth Seedling $\quad$ I: $2.72,0.07,0.13,3.18 \mathrm{~mW} \mathrm{~m}^{-2}, \mathrm{t}=56 \mathrm{~d}$} \\
\hline $\begin{array}{l}3 \text { UV-B filters in greenhouse, } \\
4 \text { random replicates, } 3 \text { hydric } \\
\text { regimes. }\end{array}$ & $\begin{array}{l}\text { UV+WS: } \downarrow \text { Flavonoids at low } \\
\text { concentrations of UV-B light } \\
\text { compared to WS. }\end{array}$ & $\begin{array}{l}\text { UV+WS: } \downarrow \text { leaf size }(18 \%) \text {, biomass } \\
(60 \%) \text { compared to WS. }\end{array}$ & $\begin{array}{l}\text { Robson et al. } \\
(2015) \text {. }\end{array}$ \\
\hline \multicolumn{4}{|c|}{ Capsicum annuum L. Plant $\lambda: 300 \mathrm{~nm}, \mathrm{I}: 80 \mathrm{~mW} \mathrm{~m}^{-2}, \mathrm{t}: 4 \mathrm{~h} \mathrm{~d}^{-1}$} \\
\hline $\begin{array}{l}4 \mathrm{~T} \text { with } 2 \text { irrigation levels, UV-B } \\
\text { irradiation for } 14 \mathrm{~d} \text {, }\end{array}$ & $\begin{array}{l}\text { UV+WS: } \uparrow \text { Flavonoids }(100 \%) \text { in } \\
\text { comparison with WS. }\end{array}$ & $\begin{array}{l}\text { UV+WS: } \downarrow \text { Stem length }(8.5 \%) \text {, leaf } \\
\text { area }(18 \%) \text { compared to WS. }\end{array}$ & $\begin{array}{l}\text { Rodríguez-Calzada } \\
\text { et al. (2019). }\end{array}$ \\
\hline
\end{tabular}
$4 \mathrm{~h}$ daily.

Oryza sativa L. Seedling $\lambda: 280 \mathrm{~nm}$, Irradiation: $6 \mathrm{~kJ} \mathrm{~m}^{-2}$

Plants induced to stress by $\mathrm{NaCl}$ and PEG, UV-B $(0,1,2,2,3,4$ and $5 \mathrm{~h})$ and three replicates. $\uparrow$ SOD $(>300 \%)$, CAT $(>300 \%)$,

PA $(>300 \%)$, MDA $(20 \%)$, phenols $(>200 \%)$ and proline $(82 \%)$.

Brassica oleracea L. var. Acephala Plant $\lambda: 280 \mathrm{~nm}, \mathrm{I}: 4.2 \mathrm{~W} \mathrm{~m}^{-2}, \mathrm{t}: 4 \mathrm{~h} \mathrm{~d}^{-1}$

T with WS (4, 3, 2, 2, $1 \mathrm{~d}$ without $\uparrow$ phenols, flavonoids, and irrigation), UV-B and in combination for 2,3 and antioxidant capacity as WS days increase.

$4 \mathrm{~d}$ before harvest.

Morus alba L. Plant Irradiation: 3.43 y $3.78 \mathrm{~kJ} \mathrm{~m}^{-2} \mathrm{~d}^{-1}$, $\mathrm{t}: 3$ months

Randomized complete design, $\mathrm{T}$ (UV-B, and water regime) (100 and 30\%).
Experiment in vitro, $\mathrm{T}$ with 3 concentrations of PEG 0,3 and $6 \%$.
Thomas and Puthur (2019).

Yoon et al. (2020). $\uparrow$ CAT (94\%), POD (83), SOD $\downarrow$ Dry weight, and root length (64\%) and anthocyanins (158\%). (85\%).

Magnetic field
Ficus carica L. Tissues Magnetic induction: $170 \mathrm{mT}$, t: 0, 15, 30, $60 \mathrm{~min} \mathrm{~d}^{-1}$
$\mathrm{MF}+\mathrm{PEG}(6 \%): \uparrow$ proline compared to PEG $(6 \%)$.
MF+PEG (6\%): $\uparrow$ Fresh weight, $\uparrow$ dry weight $\uparrow \mathrm{RWC}, \downarrow$ leaf area compared to PEG (6\%).
Zhang et al. (2020).

Karimi et al. (2012).

Kornarzynski et al. (2018).

$$
(13 \%), \downarrow \text { Chl b (19\%), } \downarrow
$$
Humidity $(7.78 \%)+\mathrm{MF}: \downarrow \mathrm{Chl}$ a carotenoids $(7 \%)$.

Amaranthus Seed Magnetic induction: $30 \mathrm{mT}$, f: $50 \mathrm{~Hz}, \mathrm{t}=30 \mathrm{~s}$
5 replicates for each irrigation level and 1 control.

\section{Lycopersicum esculentum L. cv StrainB Seed Magnetron model U.T.I.}

Divided plots with $16 \mathrm{~T}$ : $4 \mathrm{MF}$, 4 irrigation regimes $(100,80,60$, $60,40 \%)$ and 4 replicates.
$\mathrm{MF} /$ water+WS (40\%): $\uparrow \mathrm{Chl}$ (36\%) and carotenoids (29\%) compared to WS (40\%).
MF/seed + WS (40\%): $\uparrow$ Root length $(70 \%)$, plant $(37 \%)$, No. of leaves $(16 \%)$ and fresh weight (100\%) compared to WS (40\%).
Selim and El-Nady (2011).

T: Treatment, $\lambda$ : Wavelength, WS: Water Stress, MF = Magnetic field, DAG: Days after germination, MDA: Malondialdehyde, ABA: Abscisic acid, PA: Peroxidase activity, SOD: Superoxide dismutase. 
Table 1. Continuation

\begin{tabular}{|c|c|c|c|}
\hline Experimental criteria & Biochemical effects & Physiological effects & Reference \\
\hline \multirow{4}{*}{$\begin{array}{l}\text { Seeds treated with Bevistin and } \\
\text { Diathone and inoculated with } \\
\text { Rhizobium. }\end{array}$} & \multicolumn{2}{|c|}{ Magnetic field } & \multirow{4}{*}{ Baghel et al. (2018). } \\
\hline & Glycine $\max$ L. Seed Magn & Magnetic induction: $200 \mathrm{mT}$, t: $60 \mathrm{~min}$ & \\
\hline & $\begin{array}{l}\text { MF+WS: } \uparrow \mathrm{Chl}(37 \%) \text { and } \\
\text { carotenoids }(26 \%) \text { compared } \\
\text { to WS at flowering stage. }\end{array}$ & $\begin{array}{l}\text { MF + WS: } \uparrow \text { Plant height }(49 \%) \text {, } \\
\text { leaf area }(50 \%) \text {, root dry weight } \\
(30 \%) \text { compared to WS at pod } \\
\text { filling stage. }\end{array}$ & \\
\hline & Carum copticum Seed & Magnetic induction: $10 \mathrm{MT}$ & \\
\hline $\begin{array}{l}\text { Divided parcels completely at } \\
\text { random, } 2 \text { irrigation levels, } \\
1 \mathrm{MF} \text { and } 3 \text { replications. }\end{array}$ & - & $\begin{array}{l}\text { MF: } \uparrow \text { Seeds per plant }(15 \%) \text {, } \\
\text { seed weight }(8 \%) \text { and } \\
\text { inflorescences }(32 \%) .\end{array}$ & $\begin{array}{l}\text { Seghatoleslami et al. } \\
\text { (2015). }\end{array}$ \\
\hline
\end{tabular}

H. officinalis Seed Magnetic induction: 45, 90, 200, $250 \mathrm{mT}$, t: 5,10, 20, $30 \mathrm{~min}$

Randomized design with factorial arrangement, $4 \mathrm{MF}$, $8 \mathrm{~d}$ irrigation interval with 3 replications.
$\mathrm{CM}(200 \mathrm{mT})+\mathrm{WS}: \uparrow$ phenols (43\%) Chl (76\%), carotenoids $(45 \%)$ and $\downarrow$ lipid peroxidation $(33 \%)$ and DPPH (18\%) in comparison with WS.
MF $(200 \mathrm{mT})+\mathrm{WS}: \uparrow$ Dry
Mohammadi and
weight $(94 \%)$ compared to WS.
Roshandel (2020).

\section{$\mathrm{He}-\mathrm{Ne}$ laser}

Triticum aestivum L. cv. Seed $\lambda: 632.8 \mathrm{~nm}, \mathrm{t}: 3 \mathrm{~min}, \mathrm{I}: 5.43 \mathrm{~mW} \mathrm{~m}^{-2}$

Sterilized seeds $(0.01 \%), 3 \mathrm{~T}$ (T1: EH 50\%, T2: He-Ne laser, T3: EH 50\% + He-Ne Laser)
T3: $\uparrow$ Chl a (20\%) and b (40\%),

RWC (12\%). $\downarrow$ MDA (15\%) in comparison with $\mathrm{T} 1$.
T3: $\uparrow$ Plant height plant height $(21 \%)$, root $(35 \%)$ and dry weight $(11 \%)$ in comparison with $\mathrm{T} 1$.

Triticum aestivum L. cv Seed $\lambda: 632.8 \mathrm{~nm}, \mathrm{t}: 3 \mathrm{~min}, \mathrm{I}: 5.43 \mathrm{~mW} \mathrm{~m}^{-2}$

Sterilized seeds (0.01\%), $3 \mathrm{~T} \quad$ T3: $\uparrow$ SOD (68\%), CAT (16\%),

(T1: EH 50\%, T2: He-Ne laser, POD (28\%), APX (31\%) and $\downarrow$

T3: EH 50\% + He-Ne Laser). $\operatorname{miR} 160(68 \%), \operatorname{miR} 164, \operatorname{miR} 398$

miR408 (>100\%) in comparison

to $\mathrm{T} 1$.

Amaranthus Seed I: $3 \mathrm{~mW} \mathrm{~m}^{-2}$, t: $10 \mathrm{~s}$

5 replicates for each humidity level $(\mathrm{H})$, one control.

$\mathrm{H}(7.78 \%)+\mathrm{RL}: \downarrow \mathrm{Chl}$ a (33\%),

$\downarrow$ Chl b (31\%), $\downarrow$ carotenoids

$(20 \%)$ in comparison to $\mathrm{H}$

$(7.78 \%)$.

Salvia coccinea Seed $\lambda$ : $632 \mathrm{~nm}, \mathrm{I}: 1 \mathrm{~mW} \mathrm{~m}^{-2}, \mathrm{t}: 5,10,15,20 \mathrm{~min}$

Divided plots with $16 \mathrm{~T}: 4$

D $(40 \%)+$ RL: $\downarrow$ TSPC. D $(40 \%) \quad \downarrow$ Plant height, number of shoots irrigation levels D $(100,80,60,+\mathrm{RL}(5-10 \mathrm{~min})$ : $\uparrow \mathrm{PA} . \mathrm{D}(40 \%)+$ and leaves in all the T. and $40 \%$ ) and $4 \mathrm{t}$ of radiation (LR).

LR (15-20 min): $\downarrow$ AP compared to $\mathrm{D}(40 \%)$.

Celosia argentea Seed $\lambda: 650 \mathrm{~nm}, \mathrm{I}: 50 \mathrm{~mW}, \mathrm{t}: 0,5,10,15 \mathrm{~s}$

Random blocks with $12 \mathrm{~T}$ and 5 repetitions: 3 Irrigation intervals $\mathrm{D}(4,7$, and $10 \mathrm{~d})$ with $4 \mathrm{t}$ of laser radiation (LR). $\uparrow$ Unsaturated fatty acids, phenols, phenols $(51 \%)$ and flavonoids (44.5\%), DPPH $(40 \%)$.
$\operatorname{LR}(5 \mathrm{~s})+\mathrm{D}(7 \mathrm{~d}): \uparrow$ plant height, LR $(5 \mathrm{~s})+\mathrm{D}(10 \mathrm{~d}): \uparrow$ axillary buds, LR $(10 \mathrm{~s})+$ $\mathrm{D}(4 \mathrm{~d}): \uparrow$ root size, RL $(5 \mathrm{~s})+$ $\mathrm{D}(7 \mathrm{~d}): \uparrow$ sheet diameter.
Qiu et al. (2017).

Qiu et al. (2018).

Kornarzyński et al. (2018).

El-Sallami et al. (2019).

T: Treatment, $\lambda$ : Wavelength, WS: Water Stress, MDA: Malondialdehyde, TSPC: Total Soluble Phenolic Compounds, ABA: Abscisic acid, PA: Peroxidase activity, SOD: Superoxide dismutase, POD: Peroxidase, APX: Ascorbate peroxidase, CAT: Catalase, TSS: Total soluble sugars, Chl: Chlorophyll, RWC: Relative water content, ED: Experimental design, I: Intensity, LR: Laser radiation, $\downarrow$ : Decrease, $\uparrow$ : Increase. 
Table 1. Continuation

\begin{tabular}{|c|c|c|c|}
\hline Experimental criteria & Biochemical effects & Physiological effects & References \\
\hline \multirow{2}{*}{\multicolumn{4}{|c|}{ Laser }} \\
\hline & & & \\
\hline $\begin{array}{l}40 \text { sterilized seeds (at } 0.1 \% \text { ) } \\
\text { and } 5 \text { replicates. Induction to } \\
\text { WS with PEG in seedlings } \\
\text { with } 12 \text { d DAG. }\end{array}$ & $\begin{array}{l}\text { LR }(1 \mathrm{~min})+\text { WS }(10 \mathrm{~d}): \downarrow \\
38 \%), \text { LR }(3 \mathrm{~min})+\mathrm{WS}(10 \mathrm{~d}): \\
\downarrow(37 \%) \text { in comparison with } \\
\text { WS; POD, SOD and CAT } \uparrow \text { with } \\
\text { exposure time. }\end{array}$ & $\begin{array}{l}\text { LR }(5 \min )+\text { WS }(10 \mathrm{~d}): \uparrow \text { Plant } \\
\text { height }(13 \%) \text {. LR }(3 \mathrm{~min})+\text { WS } \\
(10 \mathrm{~d}): \uparrow \text { dry weight }(47 \%) \text { in } \\
\text { comparison with WS. }\end{array}$ & Qiu et al. (2008). \\
\hline
\end{tabular}

\section{Gamma-radiation \\ Bermuda grass Stolon Dose: 70-100 Gy}

Randomized experimental design (ED), 3 crop lines and a control.

$\begin{array}{ll}\text { 70-100 Gy + EH: } \uparrow \text { SOD, CAT, } & 70-100 \text { Gy+WS: } \uparrow \text { RWC in } \quad \text { Lu et al. (2008). } \\ \text { ASA, GSH and APX. } \downarrow \text { MDA. } & \text { comparison with EH. }\end{array}$

Salvia coccinea Seed Dose: 5, 10, 15, 20, 25 K.rad

Divided plots with $5 \mathrm{~T}$, transplanting at $40 \mathrm{~d}$ and 4 moisture levels 40, 60, 80 and $100 \%$.

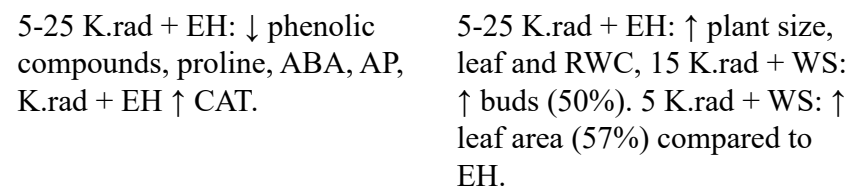

Plants treated with chitosan (pretreated with gamma radiation) with $1 \%$ acetic acid.
$100 \mathrm{KGy}+\mathrm{WS}+$ Chitosan: $\uparrow$ RWC.
El-Sallami et al. (2019).

Mirajkar et al. (2019).

photosynthesis, absence of $\quad$ RWC.

electrolytes, MDA, Proline, $\mathrm{H}_{2} \mathrm{O}_{2} \uparrow$ stomatal resistance.

Plasma

Triticum aestivum L. Seed Method: DBD, Gas: $\mathrm{NO}_{2}$ V: $13 \mathrm{Kv}$ c.a. f: $50 \mathrm{~Hz}, \mathrm{t}: 4 \mathrm{~min}$

4 T (WS, WS + Plasma, without WS, without WS + plasma).

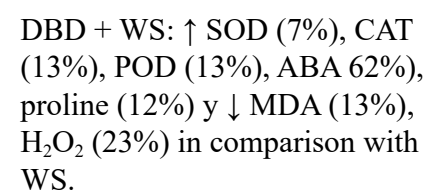

Guo et al. (2017).

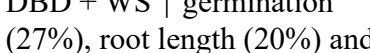


Capsicum annuum L. (Turtola et al., 2006; Feng et al., 2007; Sangtarash et al., 2009; Rodriguez-Calzada et al., 2019).

Plant heights increase in Vigna unguiculata L. and Triticum aestivum L. (Balakumar et al., 1993; Alexieva et al., 2001) and decrease in Pisum sativum L. and Triticum aestivum L. (Alexieva et al., 2001; Feng et al., 2007). Fresh weight increases in Triticum aestivum L. and Lactuca sativa L. (Alexieva et al., 2001; Basahi, 2014) and decreases in Pisum sativum L. and Rosularia elymaitica (Alexieva et al., 2001; Habibi Hajiboland, 2011). Concerning dry weight, an increase was noted in Pisum sativum L., Triticum aestivum L., Glycine max L. and Lactuca sativa L. plants (Alexieva et al., 2001; Shen et al., 2010; Basahi, 2014). However, other growth variables are also diminished in some crops, such as Rosularia elymaitica (Crassulaceae), Lactuca sativa L. and Morus alba L. (Habibi Hajiboland, 2011; Rajabbeigi et al., 2013; Zhang et al., 2020). Finally, the variable stem length decreased in Myrsinifolia, Brassica napus L. and Capsicum annuum L. cultivars (Turtola et al., 2006; Sangtarash et al., 2009; Rodríguez-Calzada et al., 2019).

A consequence of water stress has been the reduction of leaf area and combining both stressors (UV + drought) results in an improvement in the increase of leaf specific weight due to its thickening by UV (Balakumar et al., 1993). Besides, UV radiation increases the RWC factor, which may be related to the induction of osmolytes and dehydrin proteins (Alexieva et al., 2001). As mentioned above, leaf thickening, increased osmolytes, decreased leaf size, among others, lead to decreased plant transpiration, generating an increase in relative water content (Feng et al., 2007).

Thus, it is relevant to mention that UV-B light could be used to restrict cell transpiration and, consequently, counteract the adverse effects of drought in semi-arid agricultural areas, mainly in summer, when these two stressors are combined (Feng et al., 2007). Furthermore, the synergy between water stress and UV-B light improves the characteristics of the plant as opposed to single stress (Basahi et al., 2014). Therefore, according to the literature research carried out, UV radiation treatments of the seed, seedling and/or plant could be a potentially useful method to help with the problem of drought stress in the agricultural field.

Organic matter maintains a polar structure where various chemical bonds are linked to water molecules and salts that confer magnetic properties, which produces an electrostatic balance at the cell membrane level (Wever, 1968). Some authors have relied on this principle to counteract the adverse effects of drought by applying magnetic fields to plants (Radhakrishnan, 2019). Other authors like Kornarzyński et al. (2018) used a $50 \mathrm{~Hz}$ magnetic alternator to generate a $\mathrm{B}$ field of $30 \mathrm{mT}$, which was used to expose amaranth (Amaranthus) seeds for $30 \mathrm{~s}$ and found that the production of essential fatty acids and the levels of $\mathrm{Chl} \mathrm{a}$ and $\mathrm{b}$ are increased. Therefore, the production of saturated fatty acids was inhibited. Similarly, Karimi et al. (2012) applied a $170 \mathrm{mT}$ B field generated by two Alnico (AlNiCo) magnets measuring $100 \times 30 \times 20 \mathrm{~mm}$ on fig (Ficus carica L.) tissues, and even though it was under drought conditions, proline accumulation and leaf thickening were promoted, as well as water absorption.

In another study, Baghel et al. (2018) applied a static B field of $200 \mathrm{mT}$ on soybean (Glycine $\max$ L.) seeds for one hour. The magnetic stimulus employed two cylindrical polar structures of 9 and $16 \mathrm{~cm}$ in diameter and length. These authors found an increase in plant height $(5 \%)$, leaf area $(14 \%)$, root length $(3 \%)$, but root dry weight decreased (8\%). Mohammadi and Roshandel (2020) applied a B field with intensities of 45, 90, 200 and $250 \mathrm{mT}$ with exposure times of 5, 10, 20 and $30 \mathrm{~min}$. For this study, they used two magnetic coils wound around an iron core. The seeds were placed in the centre of these two coils. The authors reported that the application of $200 \mathrm{mT}$ of B field for $5 \mathrm{~min}$ increased dry weight by $94 \%, \mathrm{Chl}$ a and $\mathrm{b}(63 \%)$, and carotenoids (35\%) and reduced MDA levels (33\%) compared to plants subjected to water stress. Conversely, all plant species have survival mechanisms, specifically to water stress, since when seeds are hydrated below what is permissible, they go into a state of dormancy, postponing germination until they have the necessary conditions for germination (Kornarzyński et al., 2018).

In this sense, the B field has been used on seeds to increase germination percentage (Karimi et al., 2017). Some studies have used seed conditioning by a magnetic field to potentiate water uptake and improve germination conditions. The cell membrane permeability is affected by the effect of the B field, reflecting on the ion exchange capacity (Kornarzyński et al., 2018). Similary, Selim and El-Nady (2011) used a B field to generate tolerance to water stress in tomato (Solanum lycopersicum) plants. For this purpose, the effects were evaluated under magnetic treatments conditions on seeds, water, and both. The effects of seeds irrigated with magnetically treated water showed an increase in root length, plant height, number of leaves, number of branches, fresh and dry weight at the three irrigation levels $(80,60,40 \%)$ concerning the control groups. Inversely, Seghatoleslami et al. (2015) demonstrated that water stress and $10 \mathrm{mT}$ of B field stimulation used $30 \times 10 \mathrm{~mm}$ magnetic strips as a pre-sowing treatment of ajwain (Carum copticum) does not generate any significant effect on plant development. However, it does promote an increase in nutrient uptake in plants. On the other hand, an increase of Chl was observed in Lycopersicum esculentum L. and Glycine max L. and a decrease in Amaranthus (Kornarzynski et al., 2018; Selim and El-Nady, 2011; Baghel et al., 2018). Similarly, there is an increase of carotenoids in Lycopersicum esculentum L., Glycine max L. and H. officinalis and decrease in Amaranthus (Kornarzynski et al., 2018; Selim and El-Nady, 2011; Baghel et al., 2018; Mohammadi and Roshandel, 2020). Furthermore, an 
increase in proline has also been reported in Ficus carica L. (Karimi et al., 2012) and a decrease in lipid peroxidation and 2,2-diphenyl-1-picrylhydrazil (DPPH) radical in $H$. officinalis (Mohammadi and Roshandel, 2020).

In any case, variables of the crop have been observed with increase and decrease using B field pre-sowing. Fresh weight showed an increase in Ficus carica L. and Lycopersicum esculentum L. (Karimi et al., 2012; Selim and El-Nady, 2011) and dry weight in Ficus carica L., Glycine max L., H. officinalis (Karimi et al., 2012; Selim and El-Nady, 2011; Baghel et al., 2018; Mohammadi and Roshandel, 2020) crops have been observed. An increase in leaf area of Glycine max L. and decrease in Ficus carica L. (Karimi et al., 2012; Baghel et al., 2018) and increase in plant height and root length in Lycopersicum esculentum L. (Selim and El-Nady, 2011). Leaf area as a function of crop and type of radiation source with their respective applied parameters were negatively and positively affected. This finding could be explained due to changes in mineral absorption and increased photosynthetic activity (Selim and El-Nady, 2011; Baghel et al., 2018), having a better perception of light and nutrients available for vegetative development (De Souza-Torres et al., 1999, 2006). The B field has also affected Biomass and Chl, sometimes without changing leaf area (Selim and El-Nady, 2011; Baghel et al., 2018; Mohammadi and Roshandel, 2020). Thus, preconditioning employing low-intensity variable or constant B fields affects plant growth (Domínguez et al., 2010). Some authors have reported that in conditions without water stress, this affectation of plants is due to the production of auxins, a hormone that functions as a growth regulator that promotes cell division in tissues (Hirano et al., 1998; Leelapriya et al., 2003; Eşitken and Turan, 2004; Hernández Aguilar et al., 2009). Other authors, Leelapriya et al. (2003), also noted that the B field generates changes in growth hormones due to a change in the electrostatic balance at the cell membrane level. In this sense, the transport of hormones from the synthesis site to the fruit growth zone could be stimulated by low B field intensities (Eşitken and Turan, 2004; Hirano et al., 1998).

Improvements in other growth variables in crops without water stress have been reported, e.g., germination speed. This variable is associated with increased water uptake capacity (Karimi et al., 2017; Garcia and ArzaPascual, 2001). Due to changes in the levels of minerals, such as $\mathrm{Ca}^{2+}$ in the cell membrane, they are causing changes in calmodulin protein, increase osmosis capacity, and regulate circadian activity and phytochrome A (Leelapriya et al., 2003; Hernández-Aguilar et al., 2009). In this way, the plant's physiological and biochemical characteristics from seeds or seedlings treated with a B field (within the window of optimum levels) are improved. This is due to the fact that the stimulation improves the absorption of moisture at the seed and plant level, as has been pointed out by some authors (Flórez et al., 2007). Thus, the B field could be an alternative to drought stress due to its capacity to induce water absorption in the seed. It is necessary to determine the parameters that positively stimulate the variables of interest, such as growth, which are also a favourable consequence of the biochemical changes triggered by the B field.

Over the years, this laser has diversified its use in the agricultural field (Hernández et al., 2010; 2016). The laser bio-stimulation in seeds and plants has been shown to increase tolerance to drought stress. This process involves biochemical, physiological, and morphological changes (Thomas and Puthur, 2017), improving plant development and metabolism, photosynthetic activity, the number of stems, and root length, among other changes (Qiu et al., 2017). Laser irradiation increases the expression of genes encoding antioxidant enzymes such as ascorbic acid (AsA), GSH, SOD, CAT, POD, and APX, which enhance the tolerance to different forms of stress in plants by decreasing oxidative damage (Qiu et al., 2018; 2017). In wheat (Triticum aestivum L.) seed embryos have been exposed to $\mathrm{CO}_{2}$ laser radiation $\left(10600 \mathrm{~nm}, 20.1 \mathrm{~mW} \mathrm{~mm}^{-2}\right.$ with a $5 \mathrm{~mm}$ beam) to generate resistance to drought stress. The exposure times with the highest positive effects on the production of SOD, POD, CAT, GSH, Glutathione Reductase (GR) enzyme, APX, and a decrease in oxidizing agents such as MDA, $\mathrm{O}_{2}, \mathrm{H}_{2} \mathrm{O}_{2}$ were of 1 and $3 \mathrm{~min}$. In terms of morphological changes, the highest dry weight of the seedlings was found in the 3 min exposure time for 2, 4, 6, 8, and 10 days (Qiu et al., 2008).

A He-Ne laser ( $633 \mathrm{~nm}, 50 \mathrm{~mW})$ has been used to generate tolerance to water stress in amaranth seeds (Celosia argentea) using exposure times of 5 and $10 \mathrm{~min}$ and drought regimes of 4 and 7 days. An increased number of axillary buds, root sizes, fatty acids, phenolic compounds, flavonoids, and tannin compounds were found (Ali et al., 2020). Other studies suggest that the He-Ne laser irradiation decreases miRNA expression (miR160 and miR164) in wheat seedlings under water stress conditions. These miRNAs lead to the regulation of the expression of other genes involved in this process (Rajabbeigi et al., 2013). Conversely, Scarlet Sage (Salvia coccinea) seeds have been irradiated with He-Ne laser at $633 \mathrm{~nm}$ and at an intensity of $1 \mathrm{~mW} \mathrm{~cm}^{-2}$ with exposure times of 5,10 and $20 \mathrm{~min}$. These exposure times and intensities negatively affect plant size and the number of axillary buds (El-Sallami et al., 2019). This discovery emphasizes the need to find a window of values in which there could be a favourable response to drought tolerance, since other studies have shown that the effects of laser light can be positive, negative, or null, depending on the radiation parameters and the characteristics of the biological objects are highlighted by Hernández -Aguilar et al. (2009b; 2010; 2016).

Finally, the use of laser $\mathrm{CO}_{2}$ in experiments under water stress conditions has shown that it promotes plant growth and dry weight gain. Nevertheless, it decreases MDA and $\mathrm{H}_{2} \mathrm{O}_{2}$. On the contrary, $\mathrm{POD}, \mathrm{SOD}$, and CAT increase with 
increasing exposure time. The decrease in $\mathrm{H}_{2} \mathrm{O}_{2}$ may occur due to the laser positively effects of enzyme GR (Qiu et $a l ., 2008)$. This enzyme GR catalyses reactions to maintain high concentrations of GSH in the $\mathrm{H}_{2} \mathrm{O}_{2}$ removal pathway (Smith et al., 1989). Some authors attribute this decrease in MDA and $\mathrm{H}_{2} \mathrm{O}_{2}$ to the effect generated by $\mathrm{CO}_{2}$ on ROS (Qiu et al., 2008), which decreases the effect of free radical toxicity and oxidative damage caused by water stress (Soares et al., 2019). Conversely, the accumulation of SOD, POD and CAT mediate the production of MDA and $\mathrm{H}_{2} \mathrm{O}_{2}$ since it is known that $\mathrm{SOD}$ is the primary regulator of $\mathrm{O}_{2}$ - reducing it to $\mathrm{H}_{2} \mathrm{O}_{2}$ and $\mathrm{O}_{2}$ (Azevedo et al., 2006). Another method of great interest which has been widely studied as a pre-planting treatment is laser treatment (Hernández et al., 2010, 2016). For the specific problem of plant water stress, the type of laser which is mainly used is the He-Ne laser. It is noteworthy that, according to the literature review, when the He-Ne laser is applied, Chl a and b increases in Triticum aestivum L., and decreases in Amaranthus as well as in carotenoids (Qiu et al., 2017; Kornarzyński et al., 2018).

The result is possible because the speed of plant emergence is accelerated (Hernández et al., 2006), generating plants with a greater height, allowing them to absorb more light, which favours an increase in $\mathrm{Chl}$ and carotenoid production (Pérez-Gálvez et al., 2020). Likewise, some authors have reported an increase in dry weight (Triticum aestivum L.) and root size of Triticum aestivum L., Salvia coccinea and Celosia argentea (Qiu et al., 2017; El-Sallami et al., 2019; Ali et al., 2020). Emergence speed is related to plant growth, some authors have noted in Salvia coccinea that this variable is negatively affected when water stress is applied in conjunction with laser treatment and positively in Triticum aestivum L. and Celosia argentea (Qiu et al., 2017; Ali et al., 2020). With regard to the negative effect on plant height, it is directly associated with a water deficit in the early stages of the crop, thereby preventing proper cell division (Dichio et al., 2004). Nonetheless, in some crops such as Celosia argentea, the increase in plant height may be associated with the stimulation of cell division (Metwally et al., 2013). In experiments with Salvia coccinea and Celosia argentea cultivars using laser treatment and axillary buds are decreased and increased, respectively (El-Sallami et al., 2019; Ali et al., 2020). This increase may happen since the He-Ne laser promotes the activation of phytochromes (Hernández-Aguilar et al., 2010) which trigger growth hormone production mechanisms thereby generating cell division (Dichio et al., 2004) and consequently the emergence of axillary buds. However, when they decrease in number, which may happen due to water stress which generates small plants with apical dominance in the axillary buds (Wilson, 2000; El-Sallami et al., 2019).

In this literature review, with the application of a He-Ne laser as a method for seed improvement under drought conditions, experimental findings have shown that this treatment affects several biochemical variables. Thus, it has been reported that some of these variables increase when applying a He-Ne laser under water stress conditions (CRA, SOD, POD, CAT, and APX) and decrease (MDA, miR160, miR164, miR398 and miR408) in Triticum aestivum L. (Qiu et al., 2018). Some authors associate the He-Ne laser with the expression of genes associated with enzymes such as SOD, POD, CAT and APX, favouring their production. This gene expression process generates ROS detoxification which is produced by low humidity levels (Nawaz et al., 2015; Qiu et al., 2017).

Several authors have reported other recent studies related to secondary metabolites in the sense that the use of a He-Ne laser increases the production of these bioactive compounds (Qiu et al., 2017, 2018). Such is the case with phenols and flavonoids in Celosia argentea (Ali et al., 2020), which have been associated with the production of PAL, Cinnamic Acid 4-Hydroxylase $(\mathrm{C} 4 \mathrm{H})$, 4-CoumarateCoALigase (4CL), and Chalcone Synthase (CHS) (Cohen and Kennedy, 2010). In this way, crop disorders caused by oxidative damage in the face of a water deficit could be decreased (El-Sallami et al., 2019). In this sense, laser conditioning (at its optimal radiation parameters) is conducive to a kind of homeostasis to decrease ROS (Qiu et al., 2017). With regard to the laser radiation of seeds, another critical parameter that has been reported is fatty acids. In Celosia argentea, their concentration increased, and some authors have related this to the activation of the enzyme Delta-9Desaturase through the effects of $\mathrm{He}-\mathrm{Ne}$ laser radiation (Mckeon and Stumpf, 1982; Ali et al., 2020). Thus, more research is required to validate these hypotheses since, as may be seen in this literature review, few studies have been carried out to condition seeds using laser light and increase their tolerance to drought (Ali et al., 2020).

With regard to other biochemical variables, it should be noted that the laser light conditioning method allows for an increase in parameters such as the levels of triple superphosphate (TSP) and alkaline phosphatase (AP), among others, depending on the radiation parameters, drought level, crop type, seed characteristics and environmental conditions (El-Sallami et al., 2019). It seems that this type of laser treatment is another promising physical method to ameliorate the problem of drought, in addition to the potential benefits for plants that have been reported in other reviews and investigations (Hernández et al., 2006, 2009b, 2010, 2016). Although it does not solve the severe problem of water shortage that exists, it adds to the methods that contribute to the improvement of plant variables, despite water stress conditions.

Gamma rays are a type of ionizing radiation and are an energetic form of electromagnetic radiation which has been used to counteract the effects caused by drought (El-Sallami et al., 2019). Several authors have shown that gamma radiation induces slow growth and causes mutations that have been used to generate genetic diversity and improve tolerance to water stress (Lu et al., 2008). Gamma 
radiation was applied by El-Sallami et al. (2019) with irradiation values of $(5,10,15,15,20,20,25 \mathrm{~K} \mathrm{rad})$ at different drought levels $(100,80,60,60$, and $40 \%)$ on Jericho flower seeds (Salvia coccinea). The authors have reported that the growth variables: plant size, axillary buds, root size, and leaf diameter tend to increase when seeds are subjected to different radiation regimes, and depending on the level of radiation, these variables decrease, demonstrating a non-linear behaviour and as the level of drought increases, the variables tend to decrease.

Conversely, Mirajkar et al. (2019) found that spraying chitosan at a concentration of $200 \mathrm{ppm}$, irradiated with $100 \mathrm{KGy}$ of gamma rays on broccoli plants (Brassica oreracea $\mathrm{L}$.) subjected to drought stress, decreased the production of MDA $(31 \%)$, proline $(<100 \%)$ and total soluble sugars $(7 \%)$, and increased the production of SOD $(25 \%)$, RWC (100\%) and photosynthetic activity (116\%) representing an increase in tolerance to water stress. In the case of gamma irradiation in seed, seedling and or plant treatment processes; some reports have indicated that the variables of (SOD, CAT, ASA, GSH and APX); CAT; (stomatic resistance; CRA) increases in Bermuda grass, Salvia coccinea and Saccharum officinarum, respectively (Lu et al., 2008; El-Sallami et al., 2019; Mirajkar et al., 2019). The explanations that have offered concerning this phenomenon is that this type of ionizing radiation generates mutations at the chromosome level, altering the antioxidant enzyme activity of SOD, CAT, and APX, which was demonstrated before the drought condition (Lu et al., 2008; Hamideldin and Eliwa, 2015).

In contrast, MDA; proline; (ABA and AP); $\mathrm{H}_{2} \mathrm{O}_{2}$ decreases in Bermuda grass and Saccharum officinarum; Alvia coccinea and Saccharum officinarum; Alvia coccinea and Saccharum officinarum; Bermuda grass and Saccharum officinarum, respectively (Lu et al., 2008; El-Sallami et al., 2019; Mirajkar et al., 2019). Although, other studies indicate that in Zea mays L., proline concentrations increase (Hamideldin and Eliwa, 2015). Some authors have attributed the decreases to a mutation caused by ionizing radiation being applied before subjecting the plants to drought stress. Thus, gamma radiation increases seed and plant tolerance to water stress situations due to decreased oxidative stress markers (Lu et al., 2008). Therefore, the proline level is modified due to the production of antioxidant agents generated by gamma radiation and this change may increase crop tolerance to water stress (Hamideldin and Eliwa, 2015). In this sense, the gamma radiation activity mechanisms as a seed conditioner, established under water stress conditions, still require further exploration to elucidate their possible mechanisms of action. It is essential to mention that some authors have pointed out that the decrease in proline helps to improve tolerance to drought stress and vice versa (El-Sallami et al., 2019).
With regard to growth parameters, plant and leaf size, the number of shoots and leaf area are all increased in the Salvia coccinea crop, which was established under water stress conditions and pre-sowing treatment with gamma rays (El-Sallami et al., 2019). Some authors have reported that phenols promote plant growth and development (Datta and Nanda, 1985) and protect crops from oxidative damage caused by different types of stress (Petridis et al., 2012). However, more research is required concerning the phenolic content of plants treated with gamma radiation (El-Sallami et al., 2019).

Other authors have stated that plant height depends on the dose of gamma radiation, where at low doses, plants tend to increase their height; nonetheless, at high doses, these are decreased (El-Khateeb et al., 2017; El-Sallami et al., 2019). Among the physical methods reviewed, it is worth mentioning that the effects produced in the different stages of plant growth are a function of the internal and external parameters of it, and in addition, to the methods applied and their respective parameters. Another essential aspect to mention about this physical method for seed, seedling or plant conditioning is that the technological infrastructure required for gamma radiation is undoubtedly more complex than that required for laser light, B field, and UV light treatments.

The dielectric barrier discharge (DBD) method consists of two electrodes being placed at the ends of a ceramic plate inside an isolation chamber, with an electrical power input and nitrogen mixed with air as the separation gas (Park et al., 2018). It is activated at atmospheric pressure at room temperature. DBD can generate a vacuum and ultraviolet radiation (V-UV) given the electronic transition of the plasma discharge, an E field, electrons and various active species such as free radicals, molecules, and atoms acting on the seed (Guo et al., 2017). This stimulation process could represent an improvement in tolerance to water stress, as pointed out by some authors (Molina et al., 2018).

Dielectric barrier discharge plasma with a frequency of $50 \mathrm{~Hz}$ and an AC voltage of $13 \mathrm{kV}$ (peak voltage) was used by Guo et al. (2017) where for four minutes, they treated wheat seeds (Triticum). Subsequently, the seeds were subjected to water stress and demonstrated an increase in germination percentage $(17.3 \%)$, root length $(20 \%)$, stem length $(31.9 \%)$, and in the contents of proline $(12.7 \%)$, SOD $(4.83 \%)$, CAT (22\%) and POD (34\%), and a decrease in MDA production (12.8\%). Šerá et al. (2010) used plasma as a conditioning method in oat (Avena sativa) and wheat (Triticum) seeds to accelerate root emergence and increase the production of phenolic compounds using a plasma generator equipped with a cylindrical vacuum chamber $(10 \mathrm{~L})$ drained by a rotary pump. The working gas (flow rate $=200 \mathrm{ml} \mathrm{min}^{-1}$ ) was introduced through a corundum tube (mineral resistant to high temperatures). This tube passed through a $2.45 \mathrm{MHz}$ microwave resonator (where the plasma is generated) until it reached the reactor chamber 
where the seeds were placed. The results showed that the highest germination rate in wheat and oats occurred on the fourth and third day, after three and $40 \mathrm{~min}$ of treatment. As for the growth variables: fresh root weight, root length and seedling length, a decrease was reported as exposure time increased.

In Nasturtium (Tropaeolum majus) seeds without plasma treatment, the germination percentage increases as the irrigation level increases $(750,100,1250,1500,2000$, and $2500 \mathrm{ml})$. When plasma treatment is applied at low irrigation levels $(750 \mathrm{ml})$, the germination percentage increases at 10 and $30 \mathrm{~s}$ exposure times. For plasma treatments of 30 and $300 \mathrm{~s}$, the percentage of water absorption increases by $260 \%$ during the first $25 \mathrm{~h}$ of seed imbibition (Molina et $a l ., 2018)$. Several investigations have reported that plasma as a pre-sowing treatment under water stress conditions increases the concentrations of bioactive compounds with antioxidant capacity resulting in a decrease in oxidative stress markers and damage to the tissue and at the cellular level (Gudkov et al., 2019; Thomas and Puthur, 2017; Qiu et al., 2018). These findings may be due to the exposure time and type of gas used, as the plasma penetrates the seed through its pores to generate a physiological reaction (Velichko et al., 2019). In addition, this method has also been shown to modify the surface and chemical composition of organic materials (Molina et al., 2018).

Plasma generated with $\mathrm{NO}_{2}$ gas under vacuum conditions has been described which increased SOD, CAT, POD, ABA, proline, and germination in Triticum aestivum L. seeds (Guo et al., 2017). Also, research by some authors has shown some relationship between proline accumulation and the plant defence system. For example, plants accumulate proline as a first defence mechanism against osmotic stress situations under stress conditions, thereby protecting membranes from dehydration (Selim and El-Nady, 2011). This mechanism was explained through the water stress conditions being conducive to proline accumulation, one result of which is the accumulation of proline biosynthesis enzyme (P5CS) and the reduction of proline oxidation to glutamate (Amini et al., 2015; Guo et al., 2017). Additionally, ABA also has the function of regulating plant osmotic processes (Sharp et al., 2004) and inducing genes associated with plant dehydration (Desikan et al., 2010), which may help to activate the antioxidant system to mitigate the damage caused by ROS under water stress (Hu et al., 2008, 2010). On the other hand, it is known that SOD catalyses the conversion of the $\mathrm{O}_{2}$ - radical, and CAT converts $\mathrm{H}_{2} \mathrm{O}_{2}$ into $\mathrm{O}_{2}$ and $\mathrm{H}_{2} \mathrm{O}$. In this way, oxidative damage produced by ROS is decreased (Guo et al., 2017).

The germination variable is also affected by the physical treatment of this type; in the case of the plasma method, if generated by dielectric barrier discharge with $\mathrm{He}$ and $\mathrm{NO}_{2}$ gas, it has been reported that increased germination and water uptake occurs in Tropaeolum majus and Triticum aestivum L. seeds, respectively (Guo et al., 2017; Molina et al., 2018). Some authors have stated that this could be the case because the seeds become more permeable due to the ionized gas degrading the cell membrane and penetrating the seed through its pores, resulting in improved germination percentages (Park et al., 2016; Ito et al., 2018; Velichko et al., 2019). Thus, it is vital to be aware of the biochemical processes generated within the plant system since these are stabilized due to ROS reduction by increasing concentrations of antioxidant agents, which could help to improve plant growth under water stress situations (Molina et al., 2018). Furthermore, it has been reported that prolonged plasma exposure times negatively affect plant height (Velichko et al., 2019). In this regard, as is the case with other physical methods, the apparent effects of some plant micro- or macro-variables directly depend on the plasma emission parameters. Therefore, it is necessary to continue to gather scientific evidence to gain an understanding of the method's effectiveness and evaluate the conditions that may be more suitable for treating certain types of seeds exposed to water stress conditions in order to establish valid protocols.

Table 1 describes the synthesis of the biophysical methods used in this literature review to generate tolerance to water stress in seeds and plants. It is possible to observe the plant material used in this experiment, its experimental criteria, the radiation parameters used, intensities and powers, exposure times and the effects produced in the biochemical parameters and physiological aspects of the different seeds, tissues, seedlings, and plants treated using different methods.

The use of physical methods, such as those addressed in this literature review, could be potentially helpful in the years to come, in the current context of ecological solutions to the ongoing environmental crisis, and therefore, following the trend of ecological solutions in the protection of the environment and human beings without sacrificing resources required by future generations, i.e., proposals for sustainable agriculture. We have found conclusive evidence that the use of certain physical methods has the potential to ameliorate crop growing problems, that is, issues with limited water supply and drought in different parts of the world. Furthermore, many mechanisms remain to be elucidated concerning future and technological developments with a more inventive approach to the agricultural field. Among these methods addressed in this literature review, the main limitations are: 1) the development of technology that can treat large areas and/or large volumes of seeds; 2) the importance of defining the favourable response window that improves biochemical variables to benefit from better plant establishment. These are the challenges that are being subjected to research by the scientific community to understand and simulate the radiation parameters that could favourably stimulate seeds with different types of stimulation and different origins in the various coordinates of the world where there is agricultural production. 
Given the current trend of ecological production that allows for organic food to be obtained, free from chemicals, at a greenhouse level, under a protected form of agriculture; the global trend will be to overcome the weaknesses of these physical methods. Due to technological advances, it will become possible to overcome and even develop portable systems to treat seeds and seedlings and plants in an open field or greenhouse conditions in situ. It would seem to be a worldwide tendency to use these physical methods in a hybrid way, i.e., in a combined way, laser light and B field or laser light and LED technology, plasma and B field, among other combinations. A synthetic perspective of the applied physical methods with their radiation parameters and the corresponding response concerning different evaluated variables are presented in Figs 4 and 5. It is possible to observe that the evaluated response variables increased or decreased with the physical conditioning method used depending on the plant species concerned.

\section{CONCLUSIONS}

1. According to the literature review, most authors agree that physical methods (ultraviolet light, magnetic field, $\mathrm{He}-\mathrm{Ne}$, and $\mathrm{CO}_{2}$ lasers, gamma-rays, plasma) can be used to counteract the effects of drought on crops. The methods which are most studied and accessible are those involving UV light, He-Ne laser, and magnetic fields, followed by plasma. Several authors have focused their studies on cereals, vegetables, ornamentals, grasses, legumes, trees, fruits, and medicinal plants. Each method is characterized by specific parameters such as intensity, radiation, wavelength, frequency, type of gas used, and applied magnetic induction, which, when used to treat seeds and plants, generate effects at the biochemical and physiological level and may be positive, negative, or null. It is essential to note that these effects are a function of the parameters of each method, the induction to drought (environmental or generated), and the characteristics and phenological stage of the seeds and plants.

2. The ultraviolet light method increased the production of compounds that improve plant performance under water stress (catalase, peroxidase, anthocyanins, and proline). Magnetic fields increased proline and decreased lipid peroxidation and antioxidant activity in the studied crops. In the case of the Helium-Neon laser, most authors report an increase in carotenoids, phenols, and chlorophyll. With gamma radiation, the results are a decrease in proline and malondialdehyde and an increase in catalase. The physical plasma method increased peroxide dismutase, superoxide dismutase, catalase, proline and abscisic acid, and the variables that decreased were malondialdehyde and hydrogen peroxide. Finally, the application of a $\mathrm{CO}_{2}$ laser increases peroxide dismutase, superoxide dismutase and catalase and decreases malondialdehyde and hydrogen peroxide.
3. With regard to physiological parameters, when applying ultraviolet light to seeds, plants, and seedlings under water stress conditions, the relative water content increased in all crops where this variable was measured. However, the authors have described negative impacts concerning plant height, fresh weight and dry weight, biomass, leaf area, root length in some other species. Conversely, through the application of a magnetic field to seeds and plants under water stress conditions, an increase in root length, plant height and dry and fresh weight was generated in the crops reported by the authors. He-Ne lasers improve plant height, root length, dry weight, number of leaves and axillary buds in most of the crops studied except for Salvia coccinea where plant height, shoot size and leaf number are affected. For the gamma radiation method, relative water content increases in all treatments and plant height, leaf size, axillary buds and leaf area improve as conditioning parameters are adjusted. Furthermore, in crops grown under drought conditions, plant height, root length, and water absorption are improved when plasma is applied, and the germination percentage improves in all of the articles reviewed. Finally, when $\mathrm{CO}_{2}$ is applied to seeds, dry weight and plant height are increased.

4. In general terms, physical methods may improve plant tolerance to the drought stress of plants; the methods that are most studied and accessible are those utilizing UV light, He-Ne lasers, and magnetic fields, followed by plasma.

Conflict of interest: The authors declare no conflict of interest.

\section{REFERENCES}

Agathokleous E., Kitao M., and Calabrese E.J., 2019. Hormesis: a compelling platform for sophisticated plant science. Trends Plant. Sci., 24, 318-327. https://doi.org/10.1016/j.tplants.2019.01.004

Alexieva V., Sergiev I., Mapelli S., and Karanov E., 2001. The effect of drought and ultraviolet radiation on growth and stress markers in pea and wheat. Plant Cell Environ., 24, 1337-44.https://doi.org/10.1046/j.1365-3040.2001.00778.x

Ali S.I., Gaafar A.A., Metwally S.A., and Habba I.E., 2020. The reactive influences of pre-sowing $\mathrm{He}-\mathrm{Ne}$ laser seed irradiation and drought stress on growth, fatty acids, phenolic ingredients, and antioxidant properties of Celosia argentea. Sci. Hortic., 261, 108989.

https://doi.org/10.1016/j.scienta.2019.108989.

Amini S., Ghobadi C., and Yamchi A., 2015. Proline accumulation and osmotic stress: an overview of P5CS gene in plants. Genetics and Agricultural Biotechnology Institute of Tabarestan (GABIT), 3, 44-55.

Anders K. and Essen L.O., 2015. The family of phytochrome-like photoreceptors: diverse, complex and multi-colored, but very useful. Curr. Opin. Struct. Biol., 35, 7-16. https://doi.org/10.1016/j.sbi.2015.07.005.

Arreguin Cortes F.I., Garcia Villanueva N.H., Gonzalez Casillas A., and Guillen Gonzalez J.A., 2019. Reforms in the administration of irrigation systems: Mexican experiences. Irrig. Drain, 68, 6-19. https://doi.org/10.1002/ird.2242. 
Azadi H., Keramati P., Taheri F., Rafiaani P., Teklemariam D., Gebrehiwot K., Hosseininia G., Van Passel S., Lebailly P., and Witlox F., 2018. Agricultural land conversion: Reviewing drought impacts and coping strategies. Int. J.Disaster Risk Sci., 31, 184-195.

https://doi.org/10.1016/j.ijdrr.2018.05.003.

Baghel L., Kataria S., and Guruprasad K.N., 2018. Effect of static magnetic field pretreatment on growth, photosynthetic performance and yield of soybean under water stress. Photosynthetica, 56, 718-30. https://doi.org/10.1007/s11099-017-0722-3.

Balakumar T., Vincent V.H.B., and Paliwal K., 1993. On the Interaction of UV-B Radiation (280-315 Nm) with Water Stress in Crop Plants. Physiol. Plant, 87, 217-22. https://doi.org/10.1111/j.1399-3054.1993.tb00145.x.

Basahi J., 2014. Effects of Enhanced UV-B Radiation and Drought stress on photosynthetic performance of lettuce (Lactuca sativa L. Romaine) plants. Annu. Rev. Cell. Biol., 4, 1739-56. https://doi.org/10.9734/arrb/2014/6638.

Borthwick H.A., Hendricks S.B., Parker M.W., Toole E.H., and Toole V.K., 1952. A reversible photoreaction controlling seed germination. Proc. National Academy Sci., 38, 662-666. https://doi.org/10.1073/pnas.38.8.662.

Cohen S.D. and Kennedy J.A., 2010. Plant metabolism and the environment: implications for managing phenolics. Crit. Rev. Food Sci. Nutr., 50, 620e643. https://doi.org/10.1080/10408390802603441

Damalas C.A., Koutroubas S.D., and Fotiadis S., 2019. Hydropriming effects on seed germination and field performance of faba bean in spring sowing. Agriculture, 9, 201. https://doi.org/10.3390/agriculture9090201.

Danon A. and Gallois P., 1998. UV-C radiation induces apoptotic-like changes in Arabidopsis thaliana. FEBS letters, 437, 131-136. https://doi.org/10.1016/S0014-5793(98)01208-3.

Datta K. and Nanda K., 1985. Effect of some phenolic compounds and gibberellic acid on growth and development of cheena millet (Panicum miliaceum L.). Indian J. Plant Physiol., 28, 298-302.

De Souza-Torres A., Casate R., and Porras E., 1999. Effect of magnetic treatment of tomato seeds (Lycopersicon esculentum Mill.) on germination and seedling growth (in Spanish). Invest. Agr. Prod. Prot. Veg., 14(3), 67-74.

De Souza-Torres A., Garcí D., Sueiro L., Gilart F., Porras E., and Licea L., 2006. Pre-sowing magnetic treatments of tomato seeds increase the growth and yield of plants. Bioelectromagnetics: J. Bioelectromagnetics Society, The Society for Physical Regulation in Biology and Medicine, The European Bioelectromagnetics Association, 27, 247257. https://doi.org/10.1002/bem.20206.

Desikan R., Cheung M.K., Bright J., Henson D., Hancock J.T., and Neill S.J., 2004. ABA, hydrogen peroxide and nitric oxide signaling in stomatal guard cells. J. Exp. Bot., 55, 205-212. https://doi.org/10.1093/jxb/erh033.

Dichio B.C., Xiloyannis V., Nuzzo G., Montanaro M., and Palese A.M., 2004. Postharvest regulated deficit irrigation of peach tree in a Mediterranean environment: Effects on vegetative growth and yield. Irrig. Hort. Crops Acta Hort., 664, 169-174.https://doi.org/10.17660/ActaHortic.2004.664.18
Dillard H.R., 2019. Global Food and Nutrition Security: From Challenges to Solutions August 2018 with the Title Plant Health in a Global Economy, 249, 52. https://doi.org/10.1007/s12571-019-00893-3

Domínguez Pacheco A., Hernández Aguilar C., Cruz Orea A., Carballo Carballo A., Zepeda Bautista R., and Martínez Ortíz E. M., 2010. Influence of the electromagnetic field in maize seed vigor. Rev. Fitotec., 33, 183-188. https://doi.org/10.35196/rfm.2010.2.183.

El-Khateeb M.A., Eid R.A., Mahfouze H.A., Ashor H.A., and Mabrouk R.M., 2017. Induction of mutation with gamma radiation in Helichrysum bracteatum L. and identification of mutants by molecular markers. Middle East J. Agric. Res., 6, 282-293.

El-Sallami I.H., Abdul-Hafeez E.Y., Mostafa G., and Gad M.S., 2019. Enhancement of drought tolerance in Salvia coccinea plants by irradiation with gamma and laser pre-treatments. Assiut J. Agric. Sci., 50, 102-3. https://doi.org/10.21608/ajas.2019.41859.

Eşitken A. and Turan M., 2004. Alternating magnetic field effects on yield and plant nutrient element composition of strawberry (Fragaria x ananassa cv. camarosa). Acta Agric. Scand. B Soil Plant Sci., 54, 135-139. https://doi.org/10.1080/09064710310019748.

Evenari M., 1984. Seed physiology: From ovule to maturing seed. The Botanical Review, 50, 143-170. https://doi.org/10.1007/BF02861091.

FAO, 2014. Coping with Water Scarcity in the Near East and North Africa Fact Sheet - Regional Conf. Near East (NERC32), Rome, Italy.

Feng H., Li S., Xue L., An L., and Wang X., 2007. The interactive effects of enhanced UV-B radiation and soil drought on spring wheat. S. Afr. J. Bot., 73, 429-34.

https://doi.org/10.1016/j.sajb.2007.03.008

Fitton N., Alexander P., Arnell N., Bajzelj B., Calvin K., Doelman J., Gerber J.S., Avlik P., Hasegawa T., Herrero M., Krisztin T., Van Meijl H., Powellm T., Sandsn R., Stehfest E., West P.C., and Smith P., 2019. The vulnerabilities of agricultural land and food production to future water scarcity. Glob Environ. Change, 58, 101944. https://doi.org/10.1016/j.gloenvcha.2019.101944

Flint L.H. and Mcalister E.D., 1935. Wave Lengths of radiation in the visible spectrum inhibiting the germination of light-sensitive lettuce seed. In: Smithsonian Miscellaneous Collections. Smithsonian Inst. Misc. Coll, 94, 1-11.

Flórez M., Carbonell M.V., and Martínez E., 2007. Exposure of maize seeds to stationary magnetic fields: Effects on germination and early growth. Environ. Exp. Bot., 59, 68-75. https://doi.org/10.1016/j.envexpbot.2005.10.006.

Garcia-Reina F. and Arza-Pascual L., 2001. Influence of a stationary magnetic field on water relations in lettuce seeds. Part I: theoretical considerations. Bioelectromagnetics, 22, 589-595. https://doi.org/10.1002/bem.88 
Gudkov S.V., Grinberg M.A., Sukhov V., and Vodeneev V., 2019. Effect of ionizing radiation on physiological and molecular processes in plants. J. Environ. Radioact., 202, 8-24. https://doi.org/10.1016/j.jenvrad.2019.02.001.

Guo Q., Wang Y., Zhang H., Qu G., Wang T., Sun Q., and Liang D., 2017. Alleviation of adverse effects of drought stress on wheat seed germination using atmospheric dielectric barrier discharge plasma treatment. Sci. Rep., 7, 1-14. https://doi.org/10.1038/s41598-017-16944-8.

Habibi G. and Hajiboland R., 2011. Comparison of water stress and UV radiation effects on induction of CAM and antioxidative defense in the succulent Rosularia Elymaitica (Crassulaceae). Acta Biol. Crac. Ser Bot. 53, 15-24. https://doi.org/10.2478/v10182-011-0020-5.

Hamideldin N. and Eliwa N.E., 2015. Gamma radiation and sodium azide influence on physiological aspects of maize under drought condition. Basic Rese. J. Agric. Sci. Review, 4, 5-13.

Hernández-Aguilar C.C., Carballo C.A., Artola A., and Michtchenko A., 2006. Laser irradiation effects on maize seed field performance. Seed Sci. Technol., 34(1), 193-197. https://doi.org/10.15258/sst.2006.34.1.21

Hernández-Aguilar C., Domínguez-Pacheco A., Carballo A. C., Cruz-Orea A., Ivanov R., Bonilla J.L.L., and Montañez J.P.V., 2009a. Alternating magnetic field irradiation effects on three genotype maize seed field performance. Acta Agrophysica, 14(1), 7-17.

Hernández-Aguilar C., Dominguez-Pacheco A., Cruz-Orez A., Ivanov R., Carballo-Carballo A., Zepeda-Bautista R., and Galindo Soria L., 2009b. Laser irradiation effects on field performance of maize seed genotypes. Int. Agrophys., 23, 327-332.

Hernández-Aguilar C., Domínguez P.A., Cruz O.A., Ivanov R., Carballo C.A., and Zepeda B.R., 2010. Laser in agriculture. Int. Agrophysics, 24, 407-422.

Hernández-Aguilar C., Domínguez-Pacheco A., Cruz-Orea A., Podleśna A., Rumen I., Carballo Carballo A., Pérez Reyes M.C., Sánchez Hernández G., Zepeda Bautista R., López-Bonilla J.L., 2016. Bioestimulación Láser En Semillas y Plantas. Gayana - Botanica, 73, 132-49. https://doi.org/10.4067/S0717-66432016000100015.

Hernández-Aguilar C., Domínguez-Pacheco A., Tenango M.P., Valderrama-Bravo C., Hernández M.S., Cruz-Orea A., and Ordonez-Miranda J., 2021a. Characterization of bean seeds, germination, and phenolic compounds of seedlings by UV-C radiation. J. Plant Growth Regul., 40(2), 642-655. https://doi.org/10.1007/s00344-020-10125-0

Hernández-Aguilar C., Palma-Tenango M., Miguel-Chavez R.S., Dominguez-Pacheco A., Soto-Hernández M., del Carmen Valderrama Bravo M., Ivanov R., and OrdoñezMiranda J., 2021b. Induced changes of phenolic compounds in turmeric bread by UV-C radiation. J. Food Measur. Characterization, 1-17.

https://doi.org/10.1007/s11694-021-01231-y

Hirano M., Ohta A., and Abe K., 1998. Magnetic field effects on photosynthesis and growth of the cyanobacterium Spirulina platensis. J. Ferment. Bioeng., 86, 313-316. https://doi.org/10.1016/S0922-338X(98)80136-0.
Hu X., Liu R., Li Y., Wang W., Tai F., Xue R., and Li C., 2010. Heat shock protein 70 regulates the abscisic acid-induced antioxidant response of maize to combined drought and heat stress. Plant Growth Regul., 60, 225-235. https://doi.org/10.1007/s10725-009-9436-2.

Hu X., Wang W., Li C., Zhang J., Lin M., Zhang A., and Jiang M., 2008. Cross-talks between $\mathrm{Ca}^{2+} / \mathrm{CaM}$ and $\mathrm{H}_{2} \mathrm{O}_{2}$ in abscisic acid-induced antioxidant defense in leaves of maize plants exposed to water stress. Plant Growth Regul., 55, 183-198. https://doi.org/10.1007/s10725-008-9272-9

Hussein H.F., Hail R.C.A., and Jabail W.A., 2012. Effect of magnetic field on seed germination of wheat. Walailak $\mathrm{J}$. Sci. Technol., 9, 341-345. https://doi.org/10.2004/wjst.v9i4.313.

Ihuoma S.O. and Madramootoo C.A., 2017. Recent advances in crop water stress detection. Comput. Electron. Agric., 141, 267-75. https://doi.org/10.1016/j.compag.2017.07.026.

Ito M., Oh J.S., Ohta T., Shiratani M., and Hori M., 2018. Current status and future prospects of agricultural applications using atmospheric-pressure plasma technologies. Plasma Process Polym., 15, 1700073. https://doi.org/10.1002/ppap.201700073

Kang W.H., Kim J., Yoon H.I., and Son J.E., 2020. Quantification of spectral perception of plants with light absorption of photoreceptors. Plants, 9, 556. https://doi.org/10.3390/plants9050556.

Karimi S., Eshghi S., Karimi S., and Hasan-Nezhadian S., 2017. Inducing salt tolerance in sweet corn by magnetic priming. Acta Agric. Slov., 109, 89-102. https://doi.org/10.14720/aas.2017.109.1.09.

Karimi S., Hojati S., Eshghi S., Moghaddam R.N., and Jandoust S., 2012. Magnetic exposure improves tolerance of fig 'Sabz' explants to drought stress induced in vitro. Sci. Hortic., 137, 95-99. https://doi.org/10.1016/j.scienta.2012.01.018.

Kornarzyński K., Dziwulska-Hunek A., KornarzyńskaGregorowicz A., and Sujak A., 2018. Effect of electromagnetic stimulation of amaranth seeds of different initial moisture on the germination parameters and photosynthetic pigments content. Sci. Rep., 8, 1-12. https://doi.org/10.1038/s41598-018-32305-5.

Leelapriya T., Dhilip K.S., and Narayan P.V.S., 2003. Effect of weak sinusoidal magnetic field on germination and yield of cotton (Gossypium spp.). Electromagn. Biol. Med., 22, 117125. https://doi.org/10.1081/JBC-120024621.

Lu S., Wang Z., Niu Y., Guo Z., and Huang B., 2008. Antioxidant responses of radiation-induced dwarf mutants of bermudagrass to drought stress. J. Am. Soc. Hortic. Sci., 133, 360-66. https://doi.org/10.21273/jashs.133.3.360.

Mardero S., Schmook B., López-Martínez J.O., Cicero L., Radel C., and Christman Z., 2018. The uneven influence of climate trends and agricultural policies on maize production in the Yucatan Peninsula, Mexico. Land. 7, 1-20. https://doi.org/10.3390/land7030080.

Mariz-Ponte N., Mendes R.J., Sario S., Ferreira de Oliveira J.M.P., Melo P., and Santos C., 2018. Tomato plants use non-enzymatic antioxidant pathways to cope with moderate UV-A/B Irradiation: A Contribution to the Use of UV-A/B in Horticulture. J. Plant Physiol., 221, 32-42. https://doi. org/10.1016/j.jplph.2017.11.013.

Martínez-Hernández G.B., Blanco V., Blaya-Ros P.J., TorresSánchez R., Domingo R., and Artés-Hernández F., 2020. 
Effects of $\mathrm{Uv}-\mathrm{C}$ on bioactive compounds and quality changes during shelf life of sweet cherry grown under conventional or regulated deficit irrigation. Sci. Hortic., 269, 109398. https://doi.org/10.1016/j.scienta.2020.109398.

Martínez-Sánchez A., Guirao-Martínez J., Antonio Martínez J., Lozano-Pastor P., and Aguayo E., 2019. Inducing Fungal Resistance of Spinach Treated with Preharvest Hormetic Doses of UV-C. LWT 113:108302. https://doi.org/10.1016/j.lwt.2019.108302.

McKeon T.A. and Stumpf P.K., 1982. Purification and characterization of the stearoyl-acyl carrier protein desaturase and the acyl-acyl carrier protein thioesterase from maturing seeds of safflower. J. Biol. Chem., 257, 12141-12147. https://doi.org/10.1016/s0021-9258(18)33690-1.

Metwally S.A., Abou-Ellail M., Abo-Leila B.H., and Aboud K.A., 2013. Effect of laser radiation on the growth, anatomical and biochemical genetic markers of Celosia argentea plants. Int. J. Acad. Res., 5, 200-206. https://doi.org/10.7813/2075-4124.2013/5-3/a.28.

Mirajkar S.J., Dalvi S.G., Ramteke S.D., and Suprasanna P., 2019. Foliar application of gamma radiation processed chitosan triggered distinctive biological responses in sugarcane under water deficit stress conditions. Int. J. Biol. Macromol., 139, 1212-23. https://doi.org/10.1016/j.ijbiomac.2019.08.093.

Mishra A.K., Choi S.J., and Baek K.H., 2020. Application of Ultraviolet $\mathrm{C}$ irradiation for the increased production of secondary metabolites in plants. J. Anim. Plant Sci., 30, 1082-91. https://doi.org/10.36899/JAPS.2020.5.0123.

Mohammadi R. and Roshandel R., 2020. Ameliorative Effects of a Static Magnetic Field on Hyssop (Hyssopus officinalis L.) growth and phytochemical traits under water stress. Bioelectromagnetics, 41, 403-412. https://doi.org/10.1002/bem.22278.

Molina R., López-Santos C., Gómez-Ramírez A., Vílchez A., Espinós J.P., and González-Elipe A.R., 2018. Influence of irrigation conditions in the germination of plasma treated nasturtium seeds. Sci. Rep., 8, 1-11. https://doi.org/10.1038/s41598-018-34801-0.

Murphy J.D., 1942. The influence of magnetic field on seed germination. Am. J. Bot., 29, 155.

Murray-Tortarolo G.N., Jaramillo V.J., and Larsen J., 2018. Food security and climate change: The Case of Rainfed Maize Production in Mexico. Agric. Meteorol., 253-254, 124-31. https://doi.org/10.1016/j.agrformet.2018.02.011.

Nawaz F., Ahmad R., Ashraf M.Y., Waraich E.A., and Khan S.Z., 2015. Effect of selenium foliar spray on physiological and biochemical processes and chemical constituents of wheat under drought stress. Ecotoxicol Environ. Saf., 113, 191-200. https://doi.org/10.1016/j.ecoenv.2014.12.003.

Nejat N. and Mantri N., 2017. Plant immune system: Crosstalk between Responses to Biotic and Abiotic Stresses the Missing Link in Understanding Plant Defence. Curr. Issues Mol. Biol., 23, 1-16. https://doi.org/10.21775/cimb.023.001.

Paik I. and Huq E., 2019. Plant photoreceptors: multi-functional sensory proteins and their signaling networks. Semin Cell Dev. Biol., 92, 114-21. https://doi.org/10.1016/j.semcdb.2019.03.007.

Paparella S., Araújo S.S., Rossi G., Wijayasinghe M., Carbonera D., and Balestrazzi A., 2015. Seed priming: state of the art and new perspectives. Plant Cell Reports, 34, 1281-1293. https://doi.org/10.1007/s00299-015-1784-y.
Park Y., Oh K.S., Oh J., Seok D.C., Kim S.B., Yoo S.J., and Lee M.J., 2016. The biological effects of surface dielectric barrier discharge on seed germination and plant growth with barley. Plasma Process Polym., 15, 1-8. https://doi.org/10.1002/ppap.201600056.

Pérez-Gálvez A., Viera I., and Roca M., 2020. Carotenoids and chlorophylls as antioxidants. Antioxidants, 9, 1-39. https://doi.org/10.3390/antiox9060505.

Petridis A., Therios I., Samouris G., Koundouras S., and Giannakoula A., 2012. Effect of water deficit on leaf phenolic composition, gas exchange, oxidative damage and antioxidant activity of four Greek olives (Olea europaea L.) cultivars. Plant Physiol. Biochem., 60, 1-11.

https://doi.org/10.1016/j.plaphy.2012.07.014.

Plancot B., Gügi B., Mollet J.C., Loutelier-Bourhis C., Govind S.R., Lerouge P., Follet-Gueye M.L., Vicré M., Alfonso C., Nguema-Ona E., Bardor M., and Driouich A., 2019. Desiccation Tolerance in plants: structural characterization of the cell wall hemicellulosic polysaccharides in three Selaginella species. Carbohydr. Polym., 208, 180-90. https://doi.org/10.1016/j.carbpol.2018.12.051.

Qiu Z., He Y., Zhang Y., Guo J., and Wang L., 2018. Characterization of MiRNAs and their target genes in $\mathrm{He}-\mathrm{Ne}$ laser pretreated wheat seedlings exposed to drought stress. Ecotoxicol Environ. Saf., 164, 611-17. https://doi.org/10.1016/j.ecoenv.2018.08.077.

Qiu Z., Yuan M., He Y., Li Y., and Zhang L., 2017. Physiological and transcriptome analysis of he-ne laser pretreated wheat seedlings in response to drought stress. Sci. Rep., 7, 11-13. https://doi.org/10.1038/s41598-017-06518-z.

Qiu Z.B., Liu X., Tian X.J., and Yue M., 2008. Effects of $\mathrm{CO}_{2}$ laser pretreatment on drought stress resistance in wheat. J. Photochem. Photobiol., B 90, 17-25. https://doi.org/10.1016/j.jphotobiol.2007.09.014.

Radhakrishnan R., 2019. Magnetic field regulates plant functions, growth and enhances tolerance against environmental stresses. Physiol. Mol. Biol. Plants, 25, 1107-19. https://doi.org/10.1007/s12298-019-00699-9.

Rajabbeigi E., Eichholz I., Beesk N., Ulrichs C., Kroh L.W., Rohn S., and Huyskens-Keil S., 2013. Interaction of drought stress and uv-b radiation - impact on biomass production and flavonoid metabolism in lettuce (Lactuca sativa L.). J. Appl. Bot. Food Qual., 86, 190-97. https://doi.org/10.5073/JABFQ.2013.086.026.

Rifna E.J., Ramanan K.R., and Mahendran R., 2019. Emerging Technology applications for improving seed germination. Trends Food Sci. Technol., 86, 95-108. https://doi.org/10.1016/j.tifs.2019.02.029.

Robson T.M., Hartikainen S.M., and Aphalo P.J., 2015. How does solar ultraviolet-b radiation improve drought tolerance of silver birch (Betula pendula Roth.) Seedlings?. Plant Cell Environ., 38, 953-67. https://doi.org/10.1111/pce.12405.

Rodríguez-Calzada T., Qian M., Strid Å., Neugart S., Schreiner M., Torres-Pacheco I., and Guevara-González R.G., 2019. Effect of UV-B radiation on morphology, phenolic compound production, gene expression, and subsequent drought stress responses in chili pepper (Capsicum annuum L.). Plant Physiol. Biochem., 134, 94-102. https://doi.org/10.1016/j.plaphy.2018.06.025. 
Saccon P., 2018. Water for agriculture, irrigation management. Appl. Soil Ecol., 123, 793-96 https://doi.org/10.1016/j.apsoil.2017.10.037.

Sangtarash M.H., Qaderi M.M., Chinnappa C.C., and Reid D.M., 2009. Differential sensitivity of canola (Brassica Napus) seedlings to Ultraviolet-B radiation, water stress and abscisic acid. Environ. Exp. Bot., 66, 212-19. https://doi.org/10.1016/j.envexpbot.2009.03.004.

Savostin P.V., 1964. Magnetic growth relations in plants. Planta $12,327$.

Seghatoleslami M., Feizi H., Mousav G., and Berahmand A., 2015. Effect of magnetic field and silver nanoparticles on yield and water use efficiency of Carum copticum under water stress conditions. Pol. J. Chem. Technol., 17, 110-14. https://doi.org/10.1515/pjct-2015-0016.

Selim A.F.H. and El-Nady M.F., 2011. Physio-anatomical responses of drought stressed tomato plants to magnetic field. Acta Astronautica, 69, 387-96.

https://doi.org/10.1016/j.actaastro.2011.05.025.

Šerá B., Spatenka P., Šerý M., Vrchotova N., and Hruskova I., 2010. Influence of plasma treatment on wheat and oat germination and early growth. IEEE Trans. Plasma Sci., 38, 2963-68. https://doi.org/10.1109/TPS.2010.2060728.

Shao H.B., Chu L.Y., Jaleel C.A., Manivannan P., Panneerselvam R., and Shao M.A., 2009a. Silicon effects on photosynthesis and antioxidant parameters of soybean seedlings under drought and ultraviolet-B radiation. J. Plant Physiol., 167, 1248-52.

https://doi.org/10.1016/j.jplph.2010.04.011.

Shao H.B., Chu L.Y., Jaleel C.A., Manivannan P., Panneerselvam R., and Shao M.A., 2009b. Understanding water deficit stress-induced changes in the basic metabolism of higher plants-biotechnologically and sustainably improving agriculture and the ecoenvironment in arid regions of the globe. Crit. Rev. Biotechnol., 29, 131-51. https://doi.org/10.1080/07388550902869792.

Sharp R.E., Poroyko V., Hejlek L.G., Spollen W.G., Springer G.K., Bohnert H.J., and Nguyen H.T., 2004. Root growth maintenance during water deficits: Physiology to functional genomics. J. Exp. Bot., 55, 2343-2351. https://doi.org/10.1093/jxb/erh276.

Smith I.K., Vierheller T.L., and Thorne C.A., 1989. Properties and functions of glutathione reductase in plants. Physiol. Plant, 77, 449-456. https://doi.org/10.1111/j.1399-3054.1989.tb05666.x.

Soares C., Carvalho M.E.A., Azevedo R.A., and Fidalgo F., 2019. Plants facing oxidative challenges - A little help from the antioxidant networks. Environ. Exp. Bot., 161, 4-25. https://doi.org/10.1016/j.envexpbot.2018.12.009.

Štroch M., Materová Z., Vrábl D., Karlický V., Šigut L., Nezval J., and Špunda V., 2015. Protective effect of UV-A radiation during acclimation of the photosynthetic apparatus to UV-B treatment. Plant Physiol. Biochem., 96, 90-96. https://doi.org/10.1016/j.plaphy.2015.07.017.

Surjadinata B.B., Jacobo-Velázquez D.A., and CisnerosZevallos L., 2017. UVA, UVB and UVC light enhances the biosynthesis of phenolic antioxidants in fresh-cut carrot through a synergistic effect with wounding. Molecules, 22, 1-13. https://doi.org/10.3390/molecules22040668.

Thanos C. and Georghiou K., 1988. Osmoconditioning enhances cucumber and tomato seed germinability under adverse light conditions. Isr. J. Plant Sci., 37, 1-10.
Thomas D.T. and Puthur J.T., 2019. Amplification of abiotic stress tolerance potential in rice seedlings with a low dose of UV-B seed priming. Funct. Plant Biol., 46, 455-66. https://doi.org/10.1071/FP18258.

Thomas D.T. and Puthur J.T., 2017. UV radiation priming: a means of amplifying the inherent potential for abiotic stress tolerance in crop plants. Environ. Exp. Botany, 138, 57-66. doi:10.1016/j. envexpbot.2017.03.003

Turtola S., Rousi M., Pusenius J., Yamaji K., Heiska S., Tirkkonen V., Meier B., and Julkunen-Tiitto R., 2006. Genotypic variation in drought response of willows grown under ambient and enhanced UV-B radiation. Environ. Exp. Bot., 56, 80-86. https://doi.org/10.1016/j.envexpbot.2005.01.007.

Vàsquez H., Ouhibi C., Forges M., Lizzi Y., Urban L., and Aarrouf J., 2020. Hormetic doses of UV-C light decrease the susceptibility of tomato plants to Botrytis Cinerea infection. J. Phytopathol., 168, 524-32. https://doi.org/10.1111/jph.12930.

Velichko I., Gordeev I., Shelemin A., Nikitin D., Brinar J., Pleskunov P., Choukourov A., Pazderů K., and Pulkrábek J., 2019. Plasma jet and dielectric barrier discharge treatment of wheat seeds. Plasma Chem. Plasma Proc., 39, 913-28. https://doi.org/10.1007/s11090-019-09991-8.

Waqas M.O., Korres N.E., Khan M.D., Nizami A.S., Deeba F., Ali I., and Hussain H., 2019. Advances in the concept and methods of seed priming. In: Priming and pretreatment of seeds and seedlings. Springer, Singapore.

Wang J., Zhang L., Cao Y., Qi C., Li S., Liu L., Wang G., Mao A., Ren S., and Guo Y.D., 2018. CsATAF1 positively regulates drought stress tolerance by an ABA-dependent pathway and by promoting ROS scavenging in cucumber. Plant Cell Physiol., 59, 930-45. https://doi.org/10.1093/pcp/pcy030.

Wever R., 1968. Einfluß schwacher elektro-magnetischer Felder auf die circadiane Periodik des Menschen. Die Naturwissenschaften, 55, 29-32. https://doi.org/10.1007/BF00593403.

Wilson B.F., 2000. Apical control of branch growth and angle in woody plants. Am. J. Bot., 87, 601-607. https://doi.org/10.2307/2656846.

Xu Y., Charles M.T., Luo Z., Mimee B., Tong Z., Véronneau P.Y., Roussel D., and Rolland D., 2019. Ultraviolet-C priming of strawberry leaves against subsequent Mycosphaerella Fragariae Infection involves the action of reactive oxygen species, plant hormones, and terpenes. Plant Cell Environ., 42, 815-31. https://oi.org/10.1111/pce.13491.

Yoon H.I., Zhang W., and Son J.E., 2020. Optimal duration of drought stress near harvest for promoting bioactive compounds and antioxidant capacity in kale with or without UV-B radiation in plant factories. Plant, 9, 295. https://doi.org/10.3390/plants9030295.

Zhang C., Chen M., Liu G., Huang G., Wang Y., Yang S., and Xu X., 2020. Enhanced UV-B radiation aggravates negative effects more in females than in males of morus alba saplings under drought stress. Environ. Exp. Bot., 169, 103903. http s://doi.org/10.1016/j.envexpbot.2019.103903. 